Illinois State University

ISU ReD: Research and eData

Theses and Dissertations

$10-21-2015$

\title{
Half the Art of Living: The Influence of Religion on the Relation Between Interparental Conflict and Childhood Internalizing and Externalizing Behaviors
}

Alexandra Michelle Wills

Illinois State University, allie.m.wills@gmail.com

Follow this and additional works at: https://ir.library.illinoisstate.edu/etd

Part of the Clinical Psychology Commons

\section{Recommended Citation}

Wills, Alexandra Michelle, "Half the Art of Living: The Influence of Religion on the Relation Between Interparental Conflict and Childhood Internalizing and Externalizing Behaviors" (2015). Theses and Dissertations. 482.

https://ir.library.illinoisstate.edu/etd/482

This Thesis is brought to you for free and open access by ISU ReD: Research and eData. It has been accepted for inclusion in Theses and Dissertations by an authorized administrator of ISU ReD: Research and eData. For more information, please contact ISUReD@ilstu.edu. 
HALF THE ART OF LIVING: THE INFLUENCE OF RELIGION ON THE RELATION BETWEEN INTERPARENTAL CONFLICT AND

CHILDHOOD INTERNALIZING AND

EXTERNALIZING BEHAVIORS

\begin{abstract}
Alexandra M. Wills
70 pages

Children are increasingly being raised in environments that threaten healthy development, but there are children who develop well in spite of these threats, and there are factors within children's lives that can ameliorate the negative influence of these threats some of the time (Condly, 2006; Masten, 2001; Werner, 1993). Interparental conflict is one factor that can contribute to threatening healthy development and, indeed, has been linked with a variety of negative outcomes for children, including internalizing and externalizing behaviors (Gonzales, Pitts, Hill, \& Roosa, 2000; Ingoldsby, Shaw, Owens, \& Winslow, 1999; Rhoades, 2008). Religion has been studied as a contributing factor to positive development for adolescents, but little research has been conducted regarding the relations among religion and children's social-emotional outcomes (AbdelKhalek, 2007; French, Eisenberg, Vaughn, Purwono, \& Suryanti, 2008; Holmes \& Lochman, 2012). I hypothesized that parent religiosity would function as a resilience
\end{abstract}


factor influencing the relation between interparental conflict and childhood internalizing and externalizing behaviors. A total of 219 parents ( $80.20 \%$ female) of children ages 5 to 11 years completed an online survey that included the Brief Multidimensional Measure of Religiousness/Spirituality (Fetzer Institute, 1999), Conflicts and Problem-Solving Scale (Kerig, 1996), the Pediatric Symptom Checklist (Murphy \& Jellinek, 1988), and the General Family Functioning scale of the McMaster Family Assessment Device (Epstein, Baldwin, \& Bishop, 1983). Parent participants self-identified as primarily Christian (73.06\%), but also included those who identified as Buddhist (5.93\%), Hindu (1.37\%), Jewish (6.39\%), Muslim (2.74\%), not affiliated with any religion (6.85\%), and "other" (3.65\%). Results replicated the previous significant relation between interparental conflict and childhood internalizing and externalizing behaviors, but provided no evidence that religiosity moderated this relation. To the contrary, I found that religiosity may function as a risk factor for internalizing and externalizing behaviors at high levels of family distress.

KEYWORDS: Child, Externalizing, Internalizing, Interparental Conflict, Religion 
HALF THE ART OF LIVING: THE INFLUENCE OF RELIGION ON THE RELATION BETWEEN INTERPARENTAL CONFLICT AND

CHILDHOOD INTERNALIZING AND

EXTERNALIZING BEHAVIORS

ALEXANDRA M. WILLS

A Thesis Submitted in Partial Fulfillment of the Requirements for the Degree of

MASTER OF SCIENCE

Department of Psychology

ILLINOIS STATE UNIVERSITY

2015 
ProQuest Number: 10001441

All rights reserved

INFORMATION TO ALL USERS

The quality of this reproduction is dependent upon the quality of the copy submitted.

In the unlikely event that the author did not send a complete manuscript and there are missing pages, these will be noted. Also, if material had to be removed, a note will indicate the deletion.

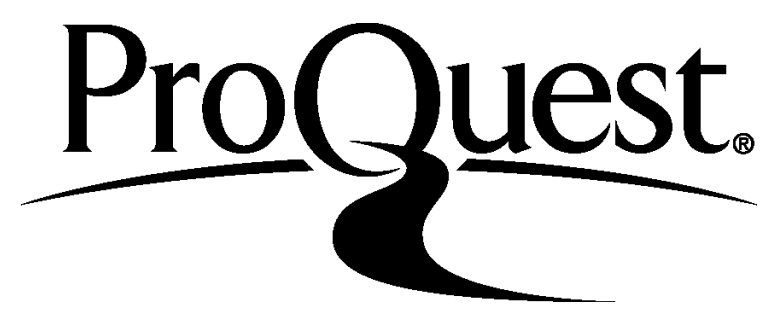

ProQuest 10001441

Published by ProQuest LLC (2016). Copyright of the Dissertation is held by the Author.

All rights reserved.

This work is protected against unauthorized copying under Title 17, United States Code Microform Edition (C) ProQuest LLC.

ProQuest LLC.

789 East Eisenhower Parkway

P.O. Box 1346

Ann Arbor, MI 48106 - 1346 
(C) 2015 Alexandra M. Wills 
HALF THE ART OF LIVING: THE INFLUENCE OF RELIGION ON THE RELATION BETWEEN INTERPARENTAL CONFLICT AND

\author{
CHILDHOOD INTERNALIZING AND
}

EXTERNALIZING BEHAVIORS

ALEXANDRA M. WILLS

COMMITTEE MEMBERS:

Renée M. Tobin, Chair

Michael J. Stevens 


\section{ACKNOWLEDGMENTS}

First and foremost, I'd like to thank Dr. Renée Tobin for her dedicated guidance through the thesis project, for her willingness to explore this topic with me, and for her tolerance of my last minute additions, my erratic schedule, and the sometimes longdistance work. My thanks are also due to Dr. Michael Stevens for his support and interest. I also owe a debt of gratitude to Dr. Joel Schneider for his help with data analysis. Finally, thank you to my wife, Megan Wills, for all her support and devotion throughout graduate school, but particularly on my thesis.

A.M.W. 


\section{CONTENTS}

Page

ACKNOWLEDGMENTS $\quad$ i

CONTENTS

TABLES $\quad$ iv

FIGURES

CHAPTER

I. THE PROBLEM AND ITS BACKGROUND 1

Resilience in Families $\quad 2$

Religion as a Resilience Factor 3

II. REVIEW OF THE LITERATURE 5

Studies Across Religions and Cultures 5

Religion, Psychopathology, and Well-Being in Adolescents $\quad 10$

Religion, Psychopathology, and Well-Being in Children 14

Religion as a Resilience Factor in Children 15

Child Versus Parent Religiosity 17

The Influence of Risk Factors 20

Inter-Parental Conflict as a Risk Factor $\quad 20$

III. RESEARCH DESIGN 23

Statement of the Problem $\quad 23$

Hypothesis 24

$\begin{array}{ll}\text { Method } & 24\end{array}$

$\begin{array}{ll}\text { Participants } & 24\end{array}$ 
Religiosity measure $\quad 28$

Interparental conflict measure $\quad 30$

$\begin{array}{ll}\text { Child behavior measure } & 30\end{array}$

Family distress measure $\quad 31$

Procedure 33

Design $\quad 33$

IV. ANALYSIS OF THE DATA 35

$\begin{array}{ll}\text { Results } & 35\end{array}$

Measure Reliability $\quad 35$

Sub-Group Comparisons $\quad 37$

Hypothesis Testing $\quad 38$

Exploratory Analyses $\quad 42$

V. SUMMARY, CONCLUSIONS, AND

RECOMMENDATIONS $\quad 48$

Summary of the Research Problem,

Methods, and Findings $\quad 48$

Implications $\quad 49$

Limitations $\quad 52$

Recommendations for Future Research 53

Conclusion $\quad 55$

REFERENCES 


\section{TABLES}

Table $\quad$ Page

1. Measures by Religious Affiliation 26

2. Participants' Gender and Sexual Orientation 27

3. Intercorrelations Among Religiosity, Interparental Conflict, Family Distress, and Children's Internalizing and Externalizing Behaviors

4. Items Used in the Scoring of Religiosity 39

5. Results for Testing the Internalizing Hypothesis 41

6. Results for Testing the Externalizing Hypothesis 42

7. Exploratory Results for Internalizing Behaviors 44

8. Exploratory Results for Externalizing Behaviors 44

9. Christian Subsample Analyses for Internalizing Behaviors 47

10. Christian Subsample Analyses for Externalizing Behaviors 47 


\section{FIGURES}

Figure

Page

1. Internalizing Exploratory Results

2. Externalizing Exploratory Results 


\section{CHAPTER I}

\section{THE PROBLEM AND ITS BACKGROUND}

"A good half of the art of living is resilience," claimed Swiss writer Alain de Botton (as cited in Lees, 2014, p. 238). Resilience is defined as "good outcomes in spite of serious threats to adaptation or development" (Masten, 2001, p. 228). Masten (2001) regards resilience as a normative process of restoration in response to positive aspects of our environment. Resilience theory holds that children are increasingly being raised in environments that threaten healthy development, that there are children who develop well in spite of these threats, and that there are factors within children's lives that can ameliorate the negative influence of these threats some of the time (Condly, 2006; Masten, 2001; Werner, 1993). Both the threat (or risk) and resilience are considered to be multi-dimensional (Condly, 2006; Fergusson \& Horwood, 2003; Luthar, Cicchetti, \& Becker, 2000; Richardson, 2002). One risk factor is not likely to ruin a child's life and one resilience factor is not likely to redeem it, but risk and resilience factors build upon each other in unique and interactive ways.

According to this theory, resilience can be fostered in those children who face adverse events in their lives. However, further research needs to be done in order to determine which factors influence children's resilience. In Werner's (1993) seminal Kauai study, the researchers examined resilience factors in an entire cohort of children on the Hawaiian island of Kauai. Werner's (1993) study found hallmarks of resilience in 
children throughout development, including a pleasant temperament in infants, autonomy in toddlers, better math and reasoning abilities in elementary students, and an achievement-oriented attitude in adolescence. Family and community characteristics, such as structured family life, substitute parents, participation in extracurricular activities, and support from a church community, were also found to be protective factors that influenced children's resilience.

\section{Resilience in Families}

While resilience in individual children was the focus of early research on the subject, relational resilience within a family has also been found to be extremely important (Condly, 2006; Walsh, 1996; Werner, 1993). Werner found that the resilient children in the Kauai study "all had at least one person in their lives who accepted them unconditionally, regardless of temperamental idiosyncrasies, physical attractiveness, or intelligence" (Werner, 1993, p. 512). Studying resilience in children is inherently relational and systemic in nature and naturally involves other people. As Bavelas and Segal (1982) argue, the patterns of family relationships that develop over time form the structure of the family system. Children, whose primary relationships and interactions are with the family, must be studied in the context of the family. As regards families' resilience, Walsh (1996) contends that "resilience involves integrating the fullness of the [challenging] experience into the fabric of individual and family identity and how family members go on to live their lives (p. 7). This outlook presupposes that families have both challenges to face and inherent strengths that they can use in the face of challenges. These strengths can include a variety of familial resilience factors such as family communication, flexibility, finances, routines, and spirituality (Black \& Lobo, 2008). As 
a family resilience factor, religion and spirituality help give the family hope and help the family members create shared meaning out of a challenge (Black \& Lobo, 2008).

\section{Religion as a Resilience Factor}

Religion is often overlooked in mental health research, despite the important role it plays in many people's lives (Loewenthal, 2000; Moreira-Almeida, Lotufo Neto, \& Koenig, 2006). Koenig (2009) defines religion as "beliefs, practices, and rituals related to the sacred [...] rooted in an established tradition" (p. 284). Hood, Hill, and Spilka (2009) elaborate, "Religion may encompass the supernatural, the non-natural, theism, deism, atheism, monotheism, polytheism, and both finite and infinite deities; it may also include practices, beliefs, and rituals that almost totally defy circumscription and definition" (p. 7). Although psychology's history is rife with the dismissal of religion, like Freud's reduction of religion to the "infantile projection of the parent figure" or Raymond Cattell's belief that humans created an afterlife to meet needs that were not met in this life, even these skeptics acknowledged the power that religion held in people's lives (Hood et al., 2009, p. 23). Furthermore, psychologists as early as William James have acknowledged the value of religion both for its positive effect and for its own merits (Hood et al., 2009). Religion can be a vital element in an individual's mental health. Religion has been identified as a resilience factor in four distinct ways: by aiding in the construction of healthy attachment, by providing social support, by facilitating the development of morals and rules for conducting oneself, and by aiding growth and personal development (Crawford, Wright, \& Masten, 2006). Religious coping is often considered separately but positive religious coping, which entails using religion to seek support and look for meaning, can be seen as a resilience factor as well (Kim \& Esquivel, 
2011; Pargament, Tarakeshwar, Ellison, \& Wulff, 2001). Religion can influence life in a variety of ways, including as a resilience factor, and may act through a variety of mechanisms.

Religion is often a prominent factor in children's family lives (Mathai \& North, 2003; Vaaler, 2008). Furthermore, religion in adults has been shown to predict positive outcomes in those who experience stress. Ai, Peterson and Huang (2003) studied 149 Kosovar and Bosnian refugee adults in order to determine, among other questions, how religious coping was related to optimism. Interestingly, the researchers did not divide the group based on religion (over $90 \%$ of participants were Muslim, but many were Catholic). Taken together, they found that positive religious coping significantly predicted optimism using structural equation modeling.

The present study aimed to extend the literature on religion as a resilience factor by studying religion in the families of children ages five to 11 . Since religious education often parallels secular education, many children's first experience with religious education begins around age 5 (Bastide, 1987; Cavaletti, 1983; Nye \& Carlson, 1984). Children have also been found to undergo significant stabilization of religious identity in this timeframe as well (Bastide, 1987; Nye \& Carlson, 1984; ter Avest, 2009). Furthermore, as emphasized later in this paper, research participants in studies about religion are generally at least adolescents. Thus, although this age is clearly a formative time for religious development, it is not often captured in the literature. 
CHAPTER II

REVIEW OF THE LITERATURE

Studies Across Religions and Cultures

Across a wide variety of cultures and religions, religiosity has been found to have a positive influence on people's lives (Abu-Rayya \& Abu-Rayya, 2009; Cochrane \& Bal, 1990; Cohen \& Hall, 2009; Fisher, Newbold, Eyles, \& Elliot, 2013; Flannelly \& Inouye, 2001; Frazier, Mintz, \& Mobley, 2005; Jang et al., 2013; Morris \& McAdie, 2009;

Pargament et al., 2001; Proffitt, Cann, Calhoun, \& Tedeschi, 2007; Suhail \& Chaudhry, 2004; Tarakeshwar, Pargament, \& Mahoney, 2003; Tiliouine, Cummins, \& Davern, 2009). Much, but not all, of this research has been done with Christian participants. Studies have found that religious people report higher levels of health and happiness. Green and Elliott (2010) studied the relation of religiosity to health and well-being. They divided participants by religious orientation, which they defined as "Catholic, Christian, [or] other" (Green \& Elliott, 2010, p. 154). Religion seems to even be related to our lifespan. In a study looking at mortality rates of one U.S. county over 28 years, those who frequently attended religious services had significantly lower mortality rates than those who attended infrequently (Strawbridge, Cohen, Shema, \& Kaplan, 1997). Hsu, Krägeloh, Shepherd, and Billington (2009) investigated the relation between religion/spirituality and quality of life in both international students and domestic 
students at a university in New Zealand. The sample was religiously diverse, with $28 \%$ identifying as Christian, 59\% identifying as non-religious, and the reminder identifying as a variety of other religions. The authors found that religion/spirituality was associated with higher perceived quality of life. Among international students, religion/spirituality was also correlated with social quality of life. The authors suggested that perhaps religion/spirituality might function as a resilience factor for international students, particularly in response to the stressors of acculturation. Associations between religiosity and psychological well-being seem to be common, in fact. In a Christian sample in Australia, there was a significant, positive association between belief in God, personal prayer, and church attendance, and psychological well-being (Francis \& Kaldor, 2002). Frazier et al. (2005) studied a sample of predominantly Christian (96\%) older AfricanAmerican adults to look at how religion was related to well-being. They found that religious involvement was associated with several dimensions of psychological wellbeing, including positive relations with others, self-acceptance, environmental mastery, purpose in life, and personal growth. Another study of older Christian adults broke religiosity down into a variety of aspects, including personal meaning, involvement in formal religion, participation in spiritual practices, importance of religion, degree of comfort derived from religion, sense of inner peace with self, and accessibility to religious resources (Fry, 2000). The study found that these aspects of religiosity predicted well-being (Fry, 2000). A Canadian study looked at differences between Old Order Mennonites, who are characterized by "no smoking, low/no alcohol consumption, high religiosity (Christian), strong family and community support, high levels of social interaction, and minimal reliance on technology," and farmers who were not Old Order 
Mennonites (Fisher et al., 2013, p. 539). They found that Old Order Mennonites had significantly better mental health than the non-Old Order Mennonite farmers. Studies on religion that look at Christianity, particularly Christianity in North America, Australia, New Zealand, and Europe, have consistently found that religiosity correlates with positive outcomes. These outcomes are frequently psychological in nature, suggesting that religion is related to psychological health in Christian adults.

Less work has been done on religions besides Christianity, but a variety of religions have still been found to have a positive effect on the lives of their practitioners, even though studies have found that different religions prioritize different aspects of faith (Cohen, Siegel, \& Rozin, 2003). Abu-Rayya \& Abu-Rayya (2009) studied 854 Palestinian young adults ranging from age 17 to age 38 . The sample was majority Muslim (61\%) with the remainder being Christian. The researchers found that religion positively correlated with psychological well-being (including higher positive affect, selfesteem, and positive social relations as well as lower negative affect) in both Muslims and Christians. Morris and McAdie's (2009) study looked at Britons who identified as Christian, Muslim, or non-religious and found that those who were religious (Christian and Muslim combined) had higher scores on well-being than those who were. However, when the religious groups were split, the relationship remained significant for Christians, but not for Muslims. This non-significant finding could be due to the small number of Muslims in the study as compared to other groups. It could also be related to their definition of religion. In Morris and McAdie's study, religion was dichotomous. In other words, they did not evaluate the intensity of one's religion, but simply compared those who identified with a religion to those who did not. Many other studies that compare 
Christians to non-Christians use similar means of defining religiousness (e.g. Cochrane \& Bal, 1990) or they use Western measures of religiosity, designed primarily for Christian samples (e.g. Ai et al., 2003). In Suhail and Chaudhry's (2004) study solely of Muslims in Pakistan, they found that religiosity was a significant predictor of subjective wellbeing. Importantly, the researchers used a religiosity scale specifically designed to measure Islamic beliefs and practices. These questions included those measuring belief in one God, belief in heaven and hell, frequency of prayers, and frequency of reciting from the Islamic holy book, the Quran. In a study of Algerian Muslims, using a measure designed specifically for Muslims, religiosity was again found to have a strong, significant positive relationship with well-being (Tiliouine et al., 2009). Overall, the existing research indicates that religiosity has as positive an influence on Muslims as it does on Christians. However, research methodology is hampered by the use of dichotomous variables for religiosity or measures that are too narrow to capture broader religiosity in a variety of religions.

Remarkably little research has been done with regards to Jewish religiosity and psychological health (Cohen \& Hall, 2009; Levin, 2013; Vilchinsky \& Kravetz, 2005). Cohen and Hall's (2009) study of older American Catholics, Protestants, and Jews found that morale was positively correlated with religiosity/spirituality only for Protestants and that Protestants reported higher well-being than either Catholics or Jews. However, the researchers used different measures of religiosity for Christians and for Jews, including questions on religious practices, knowledge, and beliefs that were specific to each group. Although providing different questions for each religious group may better capture religiosity than more generic questions, they did not demonstrate that the measures were 
equivalent. Since many Jews are likely to identify as Jewish based on a sense of ethnic identity as well as religiosity, Vilchinsky and Kravetz's (2005) study of Israeli Jews broke participants into three groups that they described as in descending order of religiosity: religious, traditional, and secular (Kedem, 1995). They found that religious belief was positively related to psychosocial well-being and negatively related to psychological distress when making within-group comparisons for just the religious and secular subgroups (Vilchinsky \& Kravetz, 2005). This relation did not hold true within the traditional group or throughout the entire sample as a whole. Thus, with what little information we have, we can see that it is likely that religiosity could have positive effects for Jews as well, although the results are not as definitive as they appear to be for Christians and Muslims. Furthermore, measurement of Jewish religiosity needs increased attention in the research.

Eastern religions such as Hinduism and Buddhism are subject to even less research than their Western counterparts. Jang et al. (2013) studied Korean women with breast cancer from different religions and the relation of their religiosity to depression and anxiety after surgery. This study found that depression and anxiety did not differ significantly among religious groups at baseline. They used the Duke Religious Index, which, although not specifically designed for Christians, has not been shown to measure religiosity in Buddhists. For Catholics, total religiosity was unrelated to depression or anxiety, but higher religious activities correlated with higher levels of depression. Among Protestants, however, total religiosity was significantly negatively correlated with anxiety and depression, while among Buddhists and those with no religious affiliation, there was no observable correlation between religiosity and depression or anxiety. These mixed 
results indicate that Catholics may be influenced by their religiosity in different ways than other Christians are or that Catholics increased their religiosity in response to their depression. The authors did not attempt to determine which factor predicted the other. This research also demonstrates that either Buddhism functions quite differently from other religions or it may need to be measured in ways that have not yet been done. Preliminary results based on a study measuring religious coping in Hindus found that religious coping was related to better mental health for Hindus as well (Tarakeshwar et al., 2003). Tarakeshwar et al. (2003) developed the Hindu religious coping scale and administered it to a sample of 164 Hindus living in the United States. They found that God-focused coping was positively related to life satisfaction and religious guilt was negatively related to life satisfaction and positively related to depression. Given the very minimal data we have, religiosity is likely related to positive outcomes for Hindus as well, although results are uncertain for Buddhists. Further research is necessary in order to determine if this pattern remains true for Hindus. A broader religious measure might also be useful for Buddhists, in order to determine whether current measures just do not adequately capture Buddhist religiosity or spirituality or if Buddhism impacts people differently than other religions.

\section{Religion, Psychopathology, and Well-Being in Adolescents}

Recent studies have shown that religion is correlated with lower psychopathology in adolescents (Abdel-Khalek, 2007; Abdel-Khalek, 2009; Abdel-Khalek \& Lester, 2007; Bullock, Nadeau, \& Renaud, 2012; Meltzer, Dogra, Vostanis, \& Ford, 2011; Pearce, Little, \& Perez, 2003; Robbins \& Francis, 2009; Scales Rostosky, Danner, \& Riggle, 
2008; Schludermann, Schludermann, \& Huynh, 2003). Houltberg, Henry, Merten, and Robinson's (2011) study of 14 to 16 year-old U.S. adolescents found no direct relation between depression and intrinsic religiosity, but did find a moderated relationship. Intrinsic religiosity is an indication that a person's religion is a directing force in their life, rather than a tool they use in order to obtain something else. Their sample consisted of 248 public high school students in order to study the relation between family connectedness, intrinsic religiosity, and depressed mood. Although family connectedness was negatively associated with depressed mood, intrinsic religiosity was not directly related to depressed mood. Their results, however, did support a model in which intrinsic religiosity moderated the relation between mothers' support and depressed mood. In a study of Kuwaiti Muslim adolescents ages 15 to 18 , religiosity was significantly and negatively correlated with scores on depression and anxiety scales (Abdel-Khalek, 2007). French, Eisenberg, Vaughn, Purwono, and Suryanti (2008) studied 12 to 14 year-old Muslim students in Indonesia. They measured spirituality using the daily spiritual experiences scale from the Brief Multidimensional Measure of Religiosity/Spirituality and religion using a scale they designed themselves specifically for Muslims in West Java in Indonesia (BMMRS). These results were combined to form one religiosity/spirituality factor. Using structural equation modeling, they found a significant negative correlation between internalizing behaviors and externalizing behaviors and religiosity/spirituality. The researchers also found that religiosity/spirituality was related to academic achievement, prosocial behavior, and self-esteem. A study of U.S. adolescents and young adults ages 11 to 23 studied the relation between religiosity and depression using the BMMRS (Desrosiers \& Miller, 2007). The participants were 
diverse, with significant numbers of black (14.6\%), Asian (17.7\%), and Latino (14.6\%) adolescents along with their white counterparts (42.6\%). Participants also included not only Christians, but also Jewish, Muslim, Buddhist, atheist, and agnostic adolescents. Desrosiers and Miller found that daily spiritual experiences, forgiveness, and religious coping were associated with less depressive symptomatology in girls. Pearce et al. (2003) used the BMMRS to examine adolescents ages 11 to 15 and found that religious attendance, self-ranking in religiosity, and positive interpersonal religious experiences negatively correlated with depressive symptoms. They also found that negative interpersonal religious experiences positively correlated with depression symptoms, suggesting that religion is an important community-level factor. These results suggest that religiosity is negatively correlated with internalizing symptoms such as anxiety and depression in youth. It is also evident from these studies that religiosity can be related to myriad factors in adolescent development. Furthermore, the BMMRS has been used among diverse groups of adolescents.

Religion has also been researched with regard to adolescent suicide (Eskin, 2004; Hilton et al., 2002; Robbins \& Francis, 2009). One study looked at 420 adolescents ages 11 to 20 who were educated in secular versus religious schools in Turkey (Eskin, 2004). Eskin found that adolescents in religious schools were less likely to consider suicide as an option compared to those in secular schools. In a study of 3,059 British 13 to 15 yearolds, Robbins and Francis (2009) found that religiosity was associated with lower levels of suicidal ideation. A study by Greening and Stoppelbein (2002), examining a large sample of white and African-American adolescents, found that commitment to core religious beliefs was significantly and negatively correlated with suicide. Although more 
studies are needed to confirm these results, existing studies indicate that religiosity is negatively correlated with suicidality in adolescents.

Religiosity affects a variety of other mental health issues in adolescents, including substance abuse (Sinha, Cnaan, \& Gelles, 2007; Wills, Yaeger, \& Sandy, 2003). Wills et al. (2003) conducted a longitudinal study of a cohort of 1,182 diverse, New York adolescents as they progressed from grades 7 through 10. The researchers found that religiosity was inversely related to alcohol, tobacco, and marijuana use. Furthermore, they found that religiosity moderated the relation between life stress and alcohol, tobacco, and marijuana use. Thus, it appears that religiosity as a moderator between stressful life events and negative outcomes is not only an appropriate model in adults, but for adolescents as well.

With regard to well-being, in Abdel-Khalek's (2011) study of Kuwaiti adolescents, he found that religiosity was significantly positively correlated with selfesteem, which could be considered an aspect of subjective well-being. In another study of Kuwaiti adolescents, Abdel-Khalek (2007) found that religiosity was positively correlated with participants' perceptions of happiness. A longitudinal study of a cohort of Muslim Indonesian adolescents as they progressed from grades 7 through 9 found that earlier religiosity predicted later adjustment, such that increased religiosity was related to increased adjustment (Sallquist, Eisenberg, French, Purwono, \& Suryanti, 2010). Schludermann et al.'s (2003) study of 444 adolescents in Mennonite high schools in Canada found that religiosity was significantly associated with prosocial values, positive attitudes about school, and family satisfaction. Studies have shown preliminary evidence 
that religion is positively related to self-esteem, happiness, positive adjustment, prosocial values, positive attitudes about school, family satisfaction, and overall well-being, suggesting that religion may be a positive force in the lives of adolescents. Studies have also shown that religion can serve as a moderator between life stressors and negative outcomes in adolescence.

\section{Religion, Psychopathology, and Well-Being in Children}

Much less research has been done relating religiosity and mental health in young children, but the patterns are similar to those for adolescents, including associations with lower levels of internalizing and externalizing behaviors and higher levels of happiness (Andrews \& Marotta, 2005; Britt, 1995; Davis \& Epkins, 2009; Jacobs, Miller, Wickramaratne, Gameroff, \& Weissman, 2012). Holmes and Lochman (2012) examined 157 African-American children ages 7 to 12 with higher levels of aggression. They determined that higher levels of parent church attendance as well as higher levels of child intrinsic religiosity, as measured by the Duke Religion Index, were related to lower levels of aggression in the children. Holder, Coleman, and Wallace's (2010) research used a modified version of the BMMRS to study 320 children ages 8 to 12 in both public and private (religious) schools. The authors found that children's spirituality/religiosity was positively correlated with their reported happiness. Religiosity in children, then, appears to follow some of the same patterns as religiosity in adults and adolescents, particularly in relation to aggression and happiness. The research, however, is quite limited and needs to be explored further. 


\section{Religion as a Resilience Factor in Children}

The evidence suggests that religion has a positive influence on children's lives. Religion can also be a resilience factor in a variety of situations, including in relation to such stressors as refugee status, homelessness, psychological distress or mental illness, physical illness, being in foster care, daily stressors, and grief (Cotton et al., 2009; Jackson et al., 2010; Williams \& Lindsey, 2005.) A qualitative study by Ní Raghallaigh and Gilligan (2010) highlighted the importance that unaccompanied immigrant minors placed on religious coping in managing the stressors related to adjusting to their new country. When asked to talk about ways they coped with acculturation-related stressors, many cited a variety of factors related to religion, including attending church with other immigrants and using religion to create a better life for themselves. Carpenter et al.'s (2012) study of 111 religious high school students found that religious coping moderated the relation between stress and depressive symptoms. Specifically, negative religious coping significantly exacerbated the effects of stress on depressive symptoms in adolescents, whereas positive religious coping only marginally buffers the effects of stress on depressive symptoms. Another study found that, among female adolescents, religious coping moderated the relation between urban stressors and depressive symptoms, although these effects disappeared when the social support dimension of religious coping was controlled for statistically (Carleton et al., 2008). Other kinds of stressors have been addressed in the literature. Cotton et al. (2009) studied the relation between religion and health in adolescents. Although the researchers found that religious coping was not significantly correlated with changes in health-related quality of life in adolescents with sickle cell disease, $35 \%$ of adolescents reported praying at least daily for 
symptom management and $73 \%$ reported they sought God's love and care with regard to their illness, indicating that the adolescents still found it an important aspect of their life. Van Dyke et al. (2009) found that positive religious coping and daily spiritual experiences were both significantly positively correlated with positive affect and life satisfaction in urban adolescents ages 11 to 14 .

Religion has also been looked at as a moderating variable between a variety of external factors and internal risk factors for the child (Davis \& Epkins, 2009; Fowler, Ahmed, Tompsett, Jozefowicz-Simbeni, \& Toro, 2008; Hair et al., 2008; Pearce, Jones, Schwab-Stone, \& Ruchkin, 2003). Ahmed, Fowler, and Toro's (2011) study of 186 urban adolescents split religiosity into private religiosity and family religiosity as measured by the Multidimensional Religiosity Scale. The authors found that, in adolescents exposed to higher levels of risk, greater private religiosity was protective from emotional and behavioral problems, whereas greater family religiosity exacerbated emotional problems. While this could indicate that parent religiosity is not an adequate proxy for child religiosity, this could be a feature of their stage of development. Since adolescents are in the process of differentiating themselves from their families, individual factors may have more positive influence on resilience (Anderson \& Sabatelli, 1990). Also, many more studies have indicated that parent religiosity can be a successful proxy for child religiosity, which I address later in this paper. In further research on urban adolescents exposed to violence, Pearce et al. (2003) found that increased religiosity (measured using the public and private religiosity scales from the BMMRS) was associated with a decrease in conduct problems. Of particular interest for this study, Davis and Epkins (2009) found that religious practices of 11 to 12 year-olds moderated the associations 
between family conflict and both youths' anxiety and youths' depression. The link between family conflict and depression and anxiety was significantly stronger for youth who were low in their religious practices (Davis \& Epkins, 2009). Religion has been researched with regards to children and adolescents as a protective factor against psychopathology in the presence of a variety of risk factors, ranging from low levels of familial support to growing up in dangerous neighborhoods, being born to adolescent mothers, experiencing chronic illnesses, and exposure to violence (Ahmed et al., 2011; Carothers Bert, 2011; Cotton et al., 2009; Houltberg, Henry, Merten, \& Robinson, 2011; Huculak, \& McLennan, 2010). However, the research presents some conflicting results and needs further validation. The literature also barely addresses the impact of religiosity on younger children.

\section{Child Versus Parent Religiosity}

Since young children in particular are primarily exposed to religion within the context of their families, parent and family religious influences on young children have often been examined (Bader \& Desmond, 2006; Goeke-Morey et al., 2013; Hair, Moore, Hadley, \& Sidorowicz, 2008; Huesmann, Dubow, \& Boxer, 2011; Jacobs et al., 2012; Kim, McCullough, \& Cicchetti, 2009; Lustig et al., 2004; Petts, 2011; Vaaler, 2008). A variety of studies have found high correlations between parent religiosity and child religiosity, so that studying a parent's religiosity can provide some perspective on the child's religiosity as well (Bader \& Desmond, 2006; Carothers Bert, 2011; Francis \& Gibson, 1993; Huesmann et al., 2011; Jacobs et al., 2012; Leonard, Cook, Boyzatis, Kimball, \& Flanagan, 2013; Okagaki \& Bevis, 1999; Schreiber, 2013). Shreiber's (2013) 
dissertation, for example, affirmed that caregivers are the primary influence on adolescents' religiosity, suggesting that looking at a caregiver's religiosity would approximate the religiosity of the teenager and his or her environment. In Schreiber's (2013) longitudinal study, religiosity was measured in 660 adolescents by two items: frequency of attendance at religious services and by how important the adolescents felt that religion was for them. Both measures of religiosity in adolescents were primarily influenced by their caregivers' religiosity. Huesmann et al.'s (2001) 40-year longitudinal study of 523 participants took that information one step further. The authors found that both grandparents' religious participation and parents' religious participation were significantly correlated with children's religious participation, without regard for the age of the child. The findings with regard to parents' influence on the religiosity of their children were longitudinal, meaning that the religious participation of a parent when the child is 8 years old was significantly correlated with that child's religious participation at age 19 and at age 48. Other research has supported the longitudinal connection between parent and child religiosity. Hair et al.'s (2008) study of 4,818 adolescents (ages 12 to 14 in the first wave) found that parent religious beliefs are positively associated with the children's religious beliefs at age 20 to 22 . These studies provide evidence to support that parent religiosity has a lasting effect on their children's own religiosity. Overall, it appears that parents' religiosity correlates significantly positively with child religiosity, as parents are the primary source of religiosity for a child.

Studies have also shown a direct relation between higher levels of parent religiosity or the religiosity of the family as a whole and lower levels of psychopathology in children (Caputo, 2004; Carothers Bert, 2011; Christian \& Barbarin, 2001; Farmer, 
Sinha, \& Gill, 2008; Goeke-Morey et al., 2013; Jacobs et al., 2012; Kim et al., 2009; Vaaler, 2008; van der Jagt-Jelsma et al., 2011). Parental religion is related to a variety of other family-level factors that could promote the resilience of the child. For example, Wolfinger and Wilcox's (2008) study found that religious participation by fathers, but not mothers, was significantly correlated with better familial relationships. In Schreiber's (2013) study of abused adolescents ages 11 to 17 , the author found that the religiosity of the caregiver after removal from the home and the religiosity of the child were both negatively correlated with delinquency in the adolescents. Kim et al. (2009) studied families of children age 6 to 12 in order to evaluate the relation between religiosity and child adjustment. They found that parents' frequency of church attendance was negatively related to levels of internalizing symptoms among children with low church attendance and that parents' reported importance of faith was negatively related to levels of both internalizing and externalizing symptoms among children with low faith. Looking at children ranging up to age 5, Petts (2011) found that weekly religious service attendance by both parents was associated with lower externalizing behaviors in their children. Having parents with strict religious beliefs, however, was associated with increased levels of internalizing behavior in children (Petts, 2011). Christian and Barbarin (2001), too, found that African-American children of parents who attended church at least weekly had fewer behavioral problems than those whose parents attended church less often. Huesmann et al. (2011) found that parents' religious participation was not only significantly inversely correlated with their child's aggression at age 8 , but also significantly inversely correlated with their grandchild's aggression 40 years later. This association holds even though the grandparents' religiosity no longer correlates with their 
own child's aggression at that later date. A study of families in Northern Ireland found that mothers' religiosity negatively correlated with child conflict, psychological distress, and adjustment problems (Goeke-Morey et al., 2013). These studies indicate that parental religiosity may indeed be related to children's psychological adjustment, but the means of measuring religiosity are still quite disparate. Further research regarding the impact of parent religiosity on children is necessary, but the current research would suggest that parent religiosity is an important family-level factor that can influence a child and may be seen as a family-level resilience factor in the child's life.

\section{The Influence of Risk Factors}

Risk factors of a variety of types have been correlated with increased internalizing and externalizing behaviors in children (Fergusson \& Horwood, 2006; Werner, 1993). Risk can be defined as a threat to the person or a threat to the positive adaptation of the child (Masten, 2011).

\section{Inter-Parental Conflict as a Risk Factor}

One all-too-common risk factor for children is inter-parental conflict (Buehler et al., 1998; Gonzales, Pitts, Hill, \& Roosa, 2000; Ingoldsby, Shaw, Owens, \& Winslow, 1999; Rhoades, 2008). Interparental conflict has been associated with a range of negative outcomes including internalizing and externalizing behaviors and self-esteem problems in children (Buehler et al., 1998; Gonzales et al., 2000; Ingoldsby et al., 1999; Rhoades, 2008). Rhoades (2008) conducted a meta-analysis of 130 studies in order to determine how children respond to interparental conflict. The author found that, in children and youth ranging in age from 5 to 19 , higher levels of interparental conflict was associated 
with increased maladaptive coping strategies, increased maladaptive cognitions, increased negative affect, increased internalizing behaviors, and increased externalizing behaviors (Rhoades, 2008). These results are further upheld by reviewing individual studies. In a longitudinal study, Ingoldsby et al. (1999) found that 2-year-old boys exposed to interparental conflict were significantly more likely to have behavior problems both at age 2 and later at age 3.5. These problems included both internalizing and externalizing behaviors. Children of all ages are impacted by interparental conflict. Buehler et al.'s (1998) study found a significant association between interparental conflict and youth problem behaviors, including both externalizing and internalizing behaviors, in youth ages 10 to 15 . The researchers found that, in particular, parents' hostile ways of managing conflict were more strongly associated with youth problem behavior than the existence of conflict per se. These negative influences of interparental conflict are not just evident during childhood. Turner and Kopiec (2006) studied 649 young adults attending college. The researchers found that report of exposure to interparental conflict in childhood or adolescence was significantly associated with more lifetime depressive episodes, lifetime substance abuse, and current depressive episodes. Thus, the research provides evidence that interparental conflict is a risk factor that can have a long-lasting impact.

A limited number of studies have been conducted looking at how religion might influence the relation between interparental conflict and adverse psychological outcomes for the child (Cox, Kotch, \& Everson, 2003; Davis \& Epkins, 2009). Davis and Epkins' (2009) study is the most relevant to the current study. The researchers evaluated whether the private religious practices of children ages 11 and 12 moderated the relation between 
family conflict and the children's depressive and anxiety symptoms. They found that the children's private religious practices moderated the relation between family conflict and both depressive and anxiety symptoms. Private religious practices, then, may protect a child against depression and anxiety when they are the sequelae of family conflict. The Cox et al. (2003) study attempted to determine whether a variety of potential factors modified the relation between intimate partner violence, which could be considered an extreme form of interparental conflict, and child maltreatment. They found that, among other factors, maternal religious attendance moderated the relation between intimate partner violence and child maltreatment such that women who were abused, but attended religious services frequently were less likely to abuse their children than abused women who seldom attended religious services. Thus, there is some evidence to suggest that religion can act as a moderating variable between a family-level stressor such as interparental conflict and negative child outcomes. 


\section{CHAPTER III}

\section{RESEARCH DESIGN}

\section{Statement of the Problem}

The current literature provides moderate evidence that religiosity (whether that of the family, parent, or child) can moderate the relation between life stressors, such as interparental conflict, and negative psychological outcomes for adolescents. However, there is little research investigating whether this pattern also holds true for children at younger ages. In an effort to investigate this question, the current study examined the influence of parents' religiosity on the relation between interparental conflict and child psychopathology. In particular, I hypothesized that parental religiosity would moderate the relation between interparental conflict and children's internalizing and externalizing behavior, while controlling for family distress. I controlled for family distress because some aspects of parental religiosity might be related to family distress. Frequency of church attendance, for example, would likely be related to family cohesion since a family with low cohesion would likely have difficulty getting organized to leave for church every week. I also looked at whether this hypothesized moderated relation exists across major religions in order to broaden the scope of the existing literature. 


\section{Hypothesis}

Parental religiosity moderates the relation between interparental conflict and children's internalizing and externalizing behavior, controlling for family distress, such that increased religiosity is associated with decreased internalizing and externalizing behavior.

\section{Method}

\section{Participants}

I recruited parent participants via craigslist.org, by contacting religious institutions, by poster advertisements, by social media, and by word of mouth. I also recruited parent participants via the staff and student listservs at Illinois State University. Participants reported on their own religiosity, conflict with their spouse or partner, and their children's internalizing and externalizing behaviors. I attempted to over-sample parents who belong to U.S. minority religions in order to include members of multiple religions. I recruited 219 parents who belong to one of the five most common religions in the United States or who are unaffiliated, which resulted in 200 participants identifying as either Christian, Jewish, Buddhist, Muslim, Hindu, or unaffiliated (Pew Forum on Religion \& Public Life, 2008). Eligible parents were those with a child aged 5 to 11 years inclusive, living in the United States, who were living with a spouse or partner, which I defined as a significant other with whom they had been living for at least 6 months regardless of the sex, gender, or sexual orientation of the significant other. Parents with more than one child were asked to answer questions based on only one randomly selected child. 
A total of 1,337 people clicked on the link leading to the survey. Of those, 635 people consented. Of those, three were removed due to having a child who did not meet the age criteria for the study and one was removed due to being polyamorous and thus not having a spouse or partner who met criteria for the study.

Not all consenting participants completed all of the measures. Of the total, 219 participants completed the BMMRS, measuring religiosity. Of those, 13 (5.93\%) identified as Buddhist, 160 (73.06\%) as Christian, 3 as Hindu (1.37\%), 14 as Jewish (6.39\%), 6 as Muslim (2.74\%), 15 as not affiliated with any religion (6.85\%), and 8 as "other" (3.65\%). (Totals do not add up to $100 \%$ because participants could choose to identify as a member of more than one religion.) Of those reporting an "other" religion, 4 identified as Unitarian Universalist with no other religion having more than one adherent. Total number of participants in each religion who completed each measure (as well as means and standard deviations) are indicated in Table 1. Compared to national data, the sample for this study includes an over-sampling of Buddhists, Hindus, Jews, and Muslims, but an under-sampling of those who selected "not affiliated."

Of those respondents who completed the demographic questionnaire, 39 (19.80\%) identified as male and $158(80.20 \%)$ as female. The reported genders of their children were more evenly split with 92 respondents identifying the target child as male (47.42\%) and 102 as female (52.58\%). Respondents' gender and their sexual orientations are shown in Table 2. Regarding the race and ethnicity of our respondents, 13 (6.91\%) identified as Hispanic/Latino(a), 12 (6.19\%) identified as Asian/Asian-American, 13 (6.70\%) identified as Black/African-American, 5 (2.58\%) identified as Native 
American/Indian, 163 (84.02\%) identified as White/Caucasian, and 6 (3.09\%) identified as "other." (Totals do not add up to $100 \%$ because participants could choose to identify as a member of more than one race and/or ethnicity.) Participants' ages ranged from 23 to 72 years $(M=39.40, s=7.37)$. Children's ages ranged from 5 to 12 years $(M=8.37$, $s=1.99$ ). Participants reported that 164 are married to their partner, 3 have a civil union, 5 have a domestic partnership, and 22 are living together. Partners' ages ranged from 21 to 70 years $(M=40.48, \mathrm{~s}=7.95)$.

Table 1

Measures by Religious Affiliation

\begin{tabular}{lccccccc}
\hline & Buddhist & Christian & Hindu & Jewish & Muslim & Unaffiliated & Other \\
\hline CPS & & & & & & & \\
Mean & 8.10 & 7.40 & 8.75 & 8.00 & 5.86 & 8.38 & 8.86 \\
SD & 2.13 & 3.31 & 3.40 & 2.27 & 2.48 & 2.99 & 2.54 \\
$n$ & 10 & 146 & 4 & 13 & 7 & 16 & 7 \\
BMMRS* & & & & & & & \\
Mean & 86.15 & 74.79 & 71.67 & 84.36 & 53.00 & 113.07 & 81.50 \\
SD & 13.02 & 16.69 & 14.84 & 17.43 & 10.99 & 6.88 & 22.82 \\
$n$ & 13 & 160 & 3 & 14 & 6 & 15 & 8 \\
PSC-Int & & & & & & & \\
Mean & 6.40 & 5.60 & 5.67 & 4.45 & 6.43 & 5.38 & 6.67 \\
SD & 7.29 & 5.44 & 2.52 & 2.73 & 3.95 & 4.98 & 7.23 \\
$n$ & 10 & 141 & 3 & 11 & 7 & 16 & 6 \\
PSC-Ext & & & & & & & \\
Mean & 5.67 & 4.00 & 8.00 & 4.67 & 3.50 & 4.33 & 5.57 \\
SD & 5.98 & 3.65 & 4.55 & 2.19 & 2.51 & 4.45 & 4.54 \\
$n$ & 9 & 140 & 4 & 12 & 6 & 15 & 7 \\
GFF & & & & & & & \\
Mean & 20.57 & 19.65 & 25.25 & 20.00 & 19.71 & 18.33 & 24.75 \\
& & & & & & $($ Table Continues)
\end{tabular}




\begin{tabular}{cccccccc}
$S D$ & 6.20 & 6.46 & 8.58 & 3.42 & 3.86 & 6.70 & 11.44 \\
$n$ & 14 & 173 & 4 & 15 & 7 & 18 & 8 \\
\hline
\end{tabular}

Note that a higher score on the BMMRS is indicative of lower religiosity.

Table 2

Participants' Gender and Sexual Orientation

\begin{tabular}{lcccc}
\hline & Bisexual/ Pansexual & Gay/lesbian & Straight & Queer \\
\hline Male & 2 & 2 & 38 & 0 \\
Female & 9 & 8 & 137 & 0 \\
\hline
\end{tabular}

\section{Measures}

All questionnaires were available for completion online. They included demographic questions about the parents and the child regarding race, age, sexual orientation, income, gender, religion, education level, and the parent's involvement in the child's life. Parent involvement was operationalized by two questions, both on a 7-point Likert scale. Demographic questions in the survey were clearly labeled as to whether they referenced the participant, the participant's partner, or the participant's child.

Demographic questions were reserved for the end of the survey in order to avoid inducing stereotype threat (Steele \& Aronson, 1995). Otherwise, the order of questionnaires was offered in two different versions. The first version started with the religiosity measure, followed by the family distress measure, then the measure for interparental conflict, and then the child behavior measure. The second version reversed the order of the first. Since the religiosity questionnaire in particular had the potential induce stereotype threat or increase a social desirability responding style, these two orders were compared in exploratory analyses of the data. 
Religiosity measure. Religiosity is often measured in religious service attendance, which may indeed be a useful proxy for Christians, but may not be useful in religions that differently emphasize worship attendance (Bagby, Perl, \& Froehle, 2001; Sayeed, 2001; Slade, 2015). In order to use a measure that better captured the religiosity of many different groups, I measured parents' reports of their own religiosity using the Fetzer Institute's (1999) Brief Multidimensional Measure of Religiousness/Spirituality. The Brief Multidimensional Measure of Religiousness/Spirituality (BMMRS) was developed as part of a large collaboration of scholars looking to measure the various dimensions in religiosity and spirituality in one instrument (King \& Crowther, 2004). Many of the subscales were originally designed to be independent measures, but were formatted to fit into the BMMRS in order to develop a more complete measure of religiosity (King \& Crowther, 2004). The BMMRS is relatively brief and easy to administer online. It has also been used with a wide variety of races and ethnicities crossnationally (Mokuau, Hishinuma, \& Nishimura, 2001; Shahabi et al., 2002; Thomas \& Freeman, 2011; Yoon \& Lee, 2004). It is a 38-item measure with a 7-point Likert-type rating scale. A lower score is indicative of higher religiosity. A sample question is, "How often do you pray privately in places other than at a church or synagogue?" with 1 indicating more than once a day and 8 indicating never. Items were originally placed into one of eight subscales: Daily Spiritual Experiences, Meaning, Values/Beliefs, Forgiveness, Spiritual Coping, Private Religious Practices, Organizational Religiousness, and Religious Support (Johnstone, McCormack, Yoon, \& Smith, 2012). In order to assess validity, these subscales were compared to the Mysticism, Transpersonal Identification, and Self-Forgetfulness subscales of the Temperament and Character Inventory in a 
sample of college students (Johnstone, Yoon, Franklin, Schopp, \& Hinkebein, 2009). All BMMRS Spirituality subscales (Daily Spiritual Experiences, Meaning, Values/Beliefs, Forgiveness, and Spiritual Coping) as well as the Organizational Religiousness subscale were significantly correlated with the TCI Mysticism Scale (Johnstone et al., 2012). Daily Spiritual Experiences and Values/Beliefs were significantly correlated with the TCI Transpersonal Identification subscale. These results support the concurrent validity of the BMMRS. In a national study, the BMMRS subscales (constructed slightly differently) all correlated highly significantly with self-reported religiosity and spirituality (Shahabi et al., 2002). Because many of the subscales started out as independent measures, the Daily Spiritual Experiences subscale of the BMMRS has been evaluated separately from the entire BMMRS (Underwood \& Teresi, 2002). The internal consistency reliability of the Daily Spiritual Experiences subscale was estimated with Cronbach's $\alpha$ at .95, which is quite high, with samples from a variety of populations including students at a religious university, female patients at an urban hospital, and arthritis patients at a rural hospital (Underwood \& Teresi, 2002). With regards to validity, the DSES was significantly positively correlated with Scheirer's Optimism Scale and Berkman's Scale of Perceived Social Support at the level of $p<.01$ with those samples (Underwood \& Teresi, 2002). In a study conducted with a racially and religiously diverse sample, it was found that respondents reporting no religion indicated the least frequent daily experience of the divine (Underwood \& Teresi, 2002). Thus, overall, the BMMRS can be said to have good reliability and validity in the contexts in which it has been studied. The BMMRS can be scored many different ways, all of which come up with a total score, but none of which use all of the items. I administered all the items, but used Idler et al.'s (2003) choice of 
items, which was used in the national General Social Survey, to conduct analyses. Other versions were also analyzed in order to determine if there was a significant difference between the versions.

Interparental conflict measure. I measured interparental conflict using the frequency/severity subscale from the Conflicts and Problem-Solving Scale (CPS; Kerig, 1996). The Conflicts and Problem-Solving Scale was designed specifically to evaluate the effect of interparental conflict on children, rather than the influence conflict has on the marital relationship (Kerig, 1996). I used the Frequency/Severity subscale score of the CPS, which measures the overall severity of the conflicts between couples as well as the frequency of the conflicts. The internal consistency for the frequency/severity subscale on the CPS was .75 with that sample (Kerig, 1996).

Child behavior measure. I measured child internalizing and externalizing behavior using the Pediatric Symptom Checklist, in particular focusing on the internalizing and externalizing factors found using principal component analysis (PSC; Jellinek, Murphy, Robinson, Feins, Lamb, \& Fenton, 1988; Reed-Knight, Hayutin, Lewis, \& Blount, 2011). The Pediatric Symptom Checklist was designed primarily to assess children's behavioral, emotional, and social functioning in a brief way in order to be used in a pediatrician's office to determine if a child and his or her family should be referred for psychological services (Murphy \& Jellinek, 1988). It has demonstrated good validity when compared to the much longer Child Behavior Checklist (CBCL), considered a standard in the field (Simonian \& Tarnowski, 2001). It is a more feasible measure in the current study considering its brevity and its ability to be administered 
online. The PSC has 35 questions parents answer about their child on a 3-point Likert scale where 1 indicates never, 2 indicates sometimes and 3 indicates often (Jellinek et al., 1988). One example item is, "Blames others for his or her troubles" (Murphy \& Jellinek, 1988). Although the questions are not divided into scales such as the CBCL's internalizing and externalizing scales, using principal component analysis researchers have found that the questions can be divided into three factors: internalizing symptoms, externalizing symptoms, and attention symptoms, which include all 35 items (ReedKnight, Hayutin, Lewis, \& Blount, 2011). One study looked at the validity of the PSC by comparing the results of 48 children's PSCs to their results on the Diagnostic Interview for Children and Adolescents (Jellinek et al., 1988). They found that the PSC has a specificity of .68 and a sensitivity of .95 with their sample, meaning the PSC correctly identified $95 \%$ of those interviewed with a psychiatric illness and correctly identified $68 \%$ of those the interviewers thought were healthy. In regards to concurrent validity, Murphy and Jellinek (1985) compared PSC scores to clinician ratings based on the Garmezy Child Interview and found that the two measures agreed $79 \%$ of the time overall. When evaluating reliability, the study authors split their sample of predominantly low-income children into those who belonged to a racial or ethnic minority and nonminority children. They found that the Pearson $r=.91$ for minority children and $r=.88$ for non-minority children. Thus, the PSC appears to have good reliability and validity in these contexts.

Family distress measure. I looked at family distress, in order to determine that our results are due to religiosity and not confounded by a latent variable of family distress. Family distress was measured using the General Family Functioning scale of the 
Family Assessment Device (FAD; Epstein, Baldwin, \& Bishop, 1983). The FAD is a 60item measure based on the McMaster Model of Family Functioning that assesses six different dimensions of family functioning and distress: problem solving, communication, roles, affective responsiveness, affective involvement, and behavior control (Epstein et al., 1983). These six dimensions form six of the seven scales with a final scale measuring general family function, or the overall health of the family with higher scores representing more family distress (Epstein et al., 1983). Cronbach's $\alpha$ for the subscales ranged from .72 to .92 in a preliminary assessment of the measure with 503 individuals, suggesting good internal consistency. In assessing validity, Epstein et al. found that the FAD correctly predicted the clinical status of $64 \%$ of those individuals whose families presented with clinical concerns and $67 \%$ of those individuals from families that did not present with clinical concerns in that sample. Their sample included inpatients in a psychiatric hospital, patients in a medical hospital, and students in an introductory psychology class. In a later study, researchers found that all but one subscale had acceptable Cronbach's $\alpha, .70$ in large samples of nonclinical, psychiatric, and medical samples (Kabacoff, Miller, Bishop, Epstein, \& Keitner, 1990). The sole subscale that was not acceptable was the roles subscale, which had marginal reliability for the psychiatric and medical samples at $\alpha=.69$, but much lower reliability in the nonclinical sample at $\alpha=.57$, which suggest that, while the other scales may be considered to have good reliability, much more caution should be used with the roles scale (Kabacoff et al., 1990). In the current study, I used only the 12 -item general functioning scale in the interest of brevity. A sample item is, "Planning family activities is difficult because we misunderstand each other" (Epstein et al., 1983). The respondents rate the items from 1 
(strongly disagree) to 4 (strongly agree) (Epstein et al., 1983). The general functioning scale has very good internal consistency within the mixed sample of Epstein et al.'s (1983) study, as demonstrated by a Cronbach's $\alpha$ of .92.

\section{Procedure}

Recruited participants were consented online and asked to confirm that they were eligible to participate. Participants then were asked to complete questionnaires including demographic questions and surveys regarding parent religiosity, inter-parental conflict, child behavior, and family distress. The surveys were available through Select Survey. The results were stored in a spreadsheet only accessible by a password-protected account. Participants who completed the study were entitled to enter a raffle and were given a link to a separate webpage that asked participants to enter in their email. The email addresses were stored separately from the results and were only used to contact those participants who won the raffle. Six $\$ 20$ gift certificates to Amazon.com were included in the raffle, for a total of $\$ 120$.

\section{Design}

In order to examine how interparental conflict and religiosity are linked with child internalizing and externalizing behaviors, I used two moderated multiple regression analyses to test the interactions between two continuous variables as a predictor of children's outcomes. I conducted separate analyses for child internalizing behaviors and externalizing behaviors (Aiken \& West, 1991). Hypothesis testing focused on the entire sample. These analyses allowed me to examine whether parent religiosity serves as a moderator of the relation between interparental conflict and children's internalizing and 
externalizing behaviors. Although adequately large sample sizes were not obtained for the remaining four religious groups (i.e., Hindus, Muslims, Jews, Buddhists, and those unaffiliated), religious group (that is, Christian versus non-Christian religion) was examined as a covariate. The relation of various demographic variables to the study variables was explored. 


\section{CHAPTER IV \\ ANALYSIS OF THE DATA}

\section{Results}

Before testing hypotheses, I conducted preliminary analyses to examine several aspects of the data. These preliminary analyses included correlations, calculating reliability for each measure, and comparisons on each measure between the different subgroups. Correlations are shown in Table 3.

Table 3

Intercorrelations Among Religiosity, Interparental Conflict, Family Distress, and Children's Internalizing and Externalizing Behaviors

\begin{tabular}{lccccc}
\hline Measure & 1 & 2 & 3 & 4 & 5 \\
\hline 1. Religiosity & - & & & & \\
2. Frequency/Severity of Conflict & $0.23^{*}$ & - & & & \\
3. Family Distress & 0.00 & $0.44^{*}$ & - & & \\
4. Child Internalizing Behaviors & -0.06 & $0.21^{*}$ & $0.41^{*}$ & - & \\
5. Child Externalizing Behaviors & -0.01 & $0.20^{*}$ & $0.41^{*}$ & $0.80^{*}$ & - \\
\hline$* \mathrm{p}<.001$ & & & & & \\
\hline
\end{tabular}

\section{Measure Reliability}

Cronbach's alpha was calculated for the various measures in order to determine the reliability of the measures selected and also to determine whether one version of the BMMRS is more reliable than others. The child internalizing behaviors subscale of the 
PSC appeared to have good internal consistency in this study, $\alpha=0.87$. The child externalizing subscale of the PSC appeared to have good internal consistency, $\alpha=0.83$. (Although not a primary variable of interest, it is worth noting that the entire PSC also had very good internal consistency, $\alpha=0.93$.) The frequency/severity measure of interparental conflict had decent internal consistency, $\alpha=0.69$. Family distress had very good internal consistency, $\alpha=0.92$.

With regards to the Brief Multi-dimensional Measure of Religiousness/Spirituality, there was some question on which version to use. The Fetzer Institute (1999) does not provide a way to calculate overall religiosity; it only provides calculations for each separate scale. Probably the most frequently cited use of the BMMRS is that of Idler et al. (2003), which previously showed reliability in a national sample. Idler et al.'s version of the BMMRS had good internal consistency, $\alpha=0.88$. Other versions were also analyzed in order to determine if a better measure of religiosity might be obtained. Rippentrop, Altmaier, Chen, Found, and Keffala's (2005) version was also found to have good internal consistency, $\alpha=0.88$. At $\alpha=0.87$ June, Segal, Coolidge, \& Klebe's (2009) version had good internal consistency. Dew et al.'s (2010) version had good internal consistency, $\alpha=0.87$. At $\alpha=0.72$, Tartaro, Luecken, \& Gunn (2005) reported the lowest alpha, but still had good internal consistency. Since none of these versions drastically improved upon Idler et al.'s choice of items, those were the items chosen when measuring religiosity. 


\section{Sub-Group Comparisons}

Independent samples $t$-tests were conducted in order to determine whether there was significant differences between various groups on the measures of interest. There was no evidence that those who completed different versions (with different orders) differed significantly on Frequency of Conflict Weighted for Severity, on Religiosity, on Family distress, on Child Internalizing Behaviors, or on Child Externalizing Behaviors. White/Caucasian respondents versus non-white/Caucasian respondents did not report significant differences for any variables of interest. Participants where one or more parent was non-straight did not report significant differences for those where both parents were straight. Male respondents versus female respondents did not report significant differences in the variables of interest except that for Child Externalizing Behaviors there was a significant effect for gender, $t(187)=2.86, p=.005$, with men reporting more externalizing symptoms in their children than women. Interestingly, participants reporting on female children versus those reporting on male children showed no significant differences on any of the variables of interest, including child externalizing and child internalizing behaviors, in which one might expect differences (Crijnen, Achenbach, \& Verhulst, 1997). Christians as compared to respondents of other religious groups (excluding those who reported not being affiliated with any religion) showed no differences on variables of interest. Those who reported no religious affiliation differed significantly from those who did report a religious affiliation on the measure of religiosity, as expected, $t(29.48)=-17.50, p<.001$, but on no other measures. Different recruitment sources (whether recruited from Illinois State University's listserv or not) demonstrated no significant differences on the variables of interest. 


\section{Hypothesis Testing}

After conducting preliminary analyses, I tested the following hypothesis: Parental religiosity moderates the relation between interparental conflict and children's internalizing and externalizing behavior, such that increased religiosity leads to decreased internalizing and externalizing behavior. Note that I did not control for family distress in this analysis because it was significantly correlated with both the predictor and criterion variables. That is, family distress is essentially the combination of how poorly the parental unit is functioning and how poorly the children are functioning. To gain a clearer understanding of the relations among the variables of interest, I initially conducted analyses without family distress as a predictor. I then conducted exploratory analyses with family distress included as a predictor and allowed this variable to interact with others in the model.

For the purposes of hypothesis testing, four variables were created. First, I created a sum for interparental conflict using the 2 items that formed the Frequency/Severity scale on the Conflicts and Problem-Solving Scale as directed in instructions provided by the author (Kerig, 1996). Then, I created a variable for religiosity based on Idler et al.'s (2003) selection of items. (Other versions of the religiosity scale were tested and were not found to be significantly different from Idler et al. (2003). Since the Idler et al. version demonstrated high reliability with previous samples, as reported earlier, and was tested on a large sample of people, Idler et al. was selected. Items in each version of the BMMRS, including Idler et al. (2003) are included in Table 4. All items were coded as numbered on the BMMRS, except those that were reverse coded, which is indicated in 
Table 3, and those which were yes-no questions (Fetzer Institute, 1999). Yes-no questions were coded 0 for no and 1 for yes as instructed (Dew et al., 2010; June, Segal, Coolidge, \& Klebe, 2009; Idler et al., 2003). Items were totaled in order to come up with a total religiosity score (Idler et al., 2003). Next, I created a variable for child internalizing behavior. Using the internalizing items found using principal component analysis in Reed-Knight et al. (2011), I totaled the following items to form my internalizing variable: $1,2,3,10,11,13,15,17,18,19,20,21,22,23,24,27$, and 30 . I followed the same procedure in order to identify variables for the externalizing variable and used the following items: 5, 12, 16, 25, 26, 29, 31, 32, 33, 34, and 35. Finally, I created a sum of family distress, using all of the items on the general family functioning scale of the Family Assessment Device.

Table 4 Items Used in the Scoring of Religiosity

\begin{tabular}{|c|c|c|c|c|}
\hline & $\begin{array}{l}\text { Idler et al. } \\
\text { (2003) }\end{array}$ & $\begin{array}{l}\text { Dew et al. } \\
(2010)\end{array}$ & $\begin{array}{l}\text { June et al. } \\
\text { (2009) }\end{array}$ & $\begin{array}{r}\text { Rippentrc } \\
(200\end{array}$ \\
\hline \multicolumn{5}{|c|}{$\begin{array}{l}\text { Daily Spiritual } \\
\text { Experiences Scale }\end{array}$} \\
\hline Item 1 & $\bullet$ & $\bullet$ & $\bullet$ & • \\
\hline Item 2 & • & $\bullet$ & $\bullet$ & • \\
\hline Item 3 & - & $\bullet$ & $\bullet$ & - \\
\hline Item 4 & - & $\bullet$ & $\bullet$ & - \\
\hline Item 5 & • & $\bullet$ & $\bullet$ & - \\
\hline Item 6 & • & $\bullet$ & $\bullet$ & $\bullet$ \\
\hline \multicolumn{5}{|c|}{ Values/Beliefs } \\
\hline Item 7 & - & & • & - \\
\hline Item 8 & • & & $\bullet$ & $\bullet$ \\
\hline Forgivene & & & & \\
\hline
\end{tabular}

(Table Continues) 


\begin{tabular}{|c|c|c|c|c|c|}
\hline & $\begin{array}{l}\text { Idler et al. } \\
(2003)\end{array}$ & $\begin{array}{l}\text { Dew et al. } \\
(2010)\end{array}$ & $\begin{array}{l}\text { June et al. } \\
\text { (2009) }\end{array}$ & $\begin{array}{l}\text { Rippentrop et al. } \\
(2005)\end{array}$ & $\begin{array}{l}\text { Tartaro et al } \\
(2005)\end{array}$ \\
\hline Item 9 & - & - & - & - & - \\
\hline Item 10 & • & $\bullet$ & • & • & $\bullet$ \\
\hline Item 11 & • & $\bullet$ & • & • & • \\
\hline \multicolumn{6}{|c|}{$\begin{array}{l}\text { Private Religious } \\
\text { Practices }\end{array}$} \\
\hline Item 12 & - & • & • & • & $\bullet$ \\
\hline Item 13 & • & • & • & • & • \\
\hline \multicolumn{6}{|l|}{ Item 14} \\
\hline Item 15 & - & $\bullet$ & • & • & $\bullet$ \\
\hline \multicolumn{6}{|l|}{ Item 16} \\
\hline \multicolumn{6}{|c|}{$\begin{array}{l}\text { Religious and Spiritual } \\
\text { Coping }\end{array}$} \\
\hline Item 17 & - & • & • & • & \\
\hline Item 18 & • & $\bullet$ & • & • & \\
\hline Item 19 & - & $\bullet$ & • & • & \\
\hline Item 20 & • & $\bullet$ & • & • & \\
\hline Item $21^{*}$ & • & • & • & • & \\
\hline Item $22 *$ & • & • & • & • & \\
\hline \multicolumn{6}{|l|}{ Item 23} \\
\hline \multicolumn{6}{|c|}{ Religious Support } \\
\hline Item 24 & • & • & • & • & \\
\hline Item 25 & • & • & • & • & \\
\hline Item $26^{*}$ & - & • & • & • & \\
\hline Item $27 *$ & • & $\bullet$ & • & • & \\
\hline \multicolumn{6}{|c|}{$\begin{array}{l}\text { Religious/ Spiritual } \\
\text { History }\end{array}$} \\
\hline Item 28 & • & • & • & & \\
\hline Item 29 & & • & • & & \\
\hline Item 30 & & • & • & & \\
\hline \multicolumn{6}{|c|}{ Commitment } \\
\hline Item 31 & $\bullet$ & • & • & & \\
\hline \multicolumn{6}{|l|}{ Item 32} \\
\hline Item 33 & & & & $(\mathrm{Ta}$ & le Continues) \\
\hline
\end{tabular}




\begin{tabular}{|c|c|c|c|c|c|}
\hline & $\begin{array}{l}\text { Idler et al. } \\
\text { (2003) }\end{array}$ & $\begin{array}{l}\text { Dew et al. } \\
\text { (2010) }\end{array}$ & $\begin{array}{l}\text { June et al. } \\
\text { (2009) }\end{array}$ & $\begin{array}{l}\text { Rippentrop et al. } \\
\text { (2005) }\end{array}$ & $\begin{array}{l}\text { Tartaro et al } \\
\quad(2005)\end{array}$ \\
\hline \multicolumn{6}{|c|}{$\begin{array}{l}\text { Organizational } \\
\text { Religiousness }\end{array}$} \\
\hline Item 34 & - & • & $\bullet$ & - & • \\
\hline Item 35 & $\bullet$ & $\bullet$ & $\bullet$ & $\bullet$ & $\bullet$ \\
\hline \multicolumn{6}{|c|}{ Overall Self-Ranking } \\
\hline Item 37 & • & $\bullet$ & & • & \\
\hline Item 38 & • & $\bullet$ & & • & \\
\hline \multicolumn{6}{|c|}{ Appendix-Meaning } \\
\hline Appendix 1 & & & - & & \\
\hline Appendix 2 & & & - & & \\
\hline
\end{tabular}

*Items were reverse coded.

**Item 36 was not included in the total score because this question asked participants what religious denomination they identified with.

To test the first hypothesis regarding children's internalizing behavior, I conducted a cross-product multiple regression analysis. When standardized scores for religiosity, interparental conflict, and the interaction term were included as predictors, there was no evidence of a significant interaction, as shown in Table 5. When the interaction term was removed, interparental conflict emerged as a significant predictor; however, there was no evidence that religiosity predicted children's internalizing behavior.

Table 5

Results for Testing the Internalizing Hypothesis

\begin{tabular}{llll}
\hline Variables & $\beta$ & $\sigma_{\beta}$ & \multicolumn{1}{c}{$t$} \\
\hline Frequency/Severity of Conflict & $.27^{*}$ & .08 & 3.30 \\
Religiosity & -.14 & .08 & -1.69 \\
Frequency/Severity of Conflict $\times$ Religiosity & -.08 & .08 & -1.01 \\
\hline
\end{tabular}
$* p<.01$ 
To test the second hypothesis regarding children's externalizing behavior, I conducted a cross-product multiple regression analysis. When standardized scores for religiosity, interparental conflict, and the interaction term were included as predictors, there was no evidence of a significant interaction, as shown in Table 6 . When the interaction term was removed, interparental conflict again emerged as a significant predictor; however, there was no evidence that religiosity predicted children's externalizing behavior.

Table 6

Results for Testing the Externalizing Hypothesis

\begin{tabular}{|c|c|c|c|}
\hline Variables & $\beta$ & $\sigma_{\beta}$ & $t$ \\
\hline Frequency/Severity of Conflict & $.26^{*}$ & .08 & 3.09 \\
\hline Religiosity & -.06 & .08 & -0.78 \\
\hline Frequency/Severity of Conflict $\times$ Religiosity & -.05 & .09 & -0.54 \\
\hline
\end{tabular}

\section{Exploratory Analyses}

I also conducted exploratory analyses with family distress included as a predictor. I conducted a multivariate multiple regression analysis (similar to a MANOVA but with continuous predictors) using standardized scores for family distress, religiosity, interparental conflict, the two-way interaction terms, and the three-way interaction as predictors for children's internalizing and externalizing behaviors, there was no evidence of a significant three-way interaction. When the three-way interaction was removed, two significant two-way interactions emerged between interparental conflict and family distress (Pillai's Trace $=.04, F(2,161)=3.41, p=.04$ ) and between religiosity and 
family distress (Pillai's Trace $=.06, F(2,161)=5.44, p=.01)$; however, there was no evidence of a significant interaction between interparental conflict and religiosity $($ Pillai's Trace $=.01, F(2,161)=0.92, p=.40)$.

In order to further explore these results, I conducted a cross-product multiple regression analysis each for internalizing and externalizing behaviors. When standardized scores for family distress, religiosity, interparental conflict, the two-way interaction terms, and the three-way interaction were included as predictors of children's internalizing behavior, no significant three-way interaction emerged. See Table 7. When standardized scores for family distress, religiosity, interparental conflict, the two-way interaction terms, and the three-way interaction were included as predictors of children's externalizing behavior, a marginally significant three-way interaction emerged. See table 8. Follow-up simple slopes analyses revealed that at low partner conflict (that is, one standard deviation below the mean) and low family distress, religiosity was not a significant predictor for either internalizing or externalizing behaviors. At low partner conflict and high family distress (that is, one standard deviation above the mean), religiosity was a significant predictor of internalizing behavior $(p=.01)$, but not of externalizing behavior. At high partner conflict and low family distress, there was no evidence that religiosity was a significant predictor of internalizing or externalizing behavior. At high partner conflict and high family distress, religiosity was a significant predictor of internalizing behavior $(p<.001)$ and externalizing behavior $(p=.04)$. At mean partner conflict and high family distress, religiosity was a significant predictor of both internalizing behavior $(p<.001)$ and externalizing behavior $(p=.03)$. At mean partner conflict and low family distress, there was no evidence that religiosity was a 
significant predictor of either internalizing or externalizing behavior. Figure 1 shows the relations for children's internalizing behaviors and Figure 2 shows the relations for externalizing behaviors.

Table 7

Exploratory Results for Internalizing Behaviors

\begin{tabular}{lccc}
\hline & $b$ & $\sigma_{b}$ & $t$ \\
\hline Frequency/Severity of Partner Conflict & 0.07 & 0.08 & 0.87 \\
Family Distress & $0.36^{*}$ & 0.08 & 4.30 \\
Religiosity & $0.15^{*}$ & 0.07 & 2.15 \\
Partner Conflict $\times$ Family Distress & $0.31^{*}$ & 0.08 & 4.03 \\
Partner Conflict $\times$ Religiosity & -0.02 & 0.09 & -0.25 \\
Family Distress $\times$ Religiosity & $0.32^{*}$ & 0.10 & 3.35 \\
Partner Conflict $\times$ Family Distress $\times$ & -0.06 & 0.08 & -0.75 \\
Religiosity & & & \\
\hline
\end{tabular}

${ }^{*} p<.05$

Table 8

Exploratory Results for Externalizing Behaviors

\begin{tabular}{lccc}
\hline & $b$ & $\sigma_{b}$ & $t$ \\
\hline Frequency/Severity of Partner Conflict & 0.08 & 0.09 & 0.97 \\
Family Distress & $0.35^{*}$ & 0.09 & 3.97 \\
Religiosity & 0.08 & 0.07 & 1.05 \\
Partner Conflict $\times$ Family Distress & $0.15 \dagger$ & 0.08 & 1.84 \\
Partner Conflict $\times$ Religiosity & -0.02 & 0.09 & -0.19 \\
Family Distress $\times$ Religiosity & $0.21^{*}$ & 0.10 & 2.10 \\
Partner Conflict $\times$ Family Distress $\times$ & $0.16 \dagger$ & 0.08 & 0.05 \\
Religiosity & & & \\
\hline
\end{tabular}

${ }^{*} p<.05 ; \dagger p<.10$ 


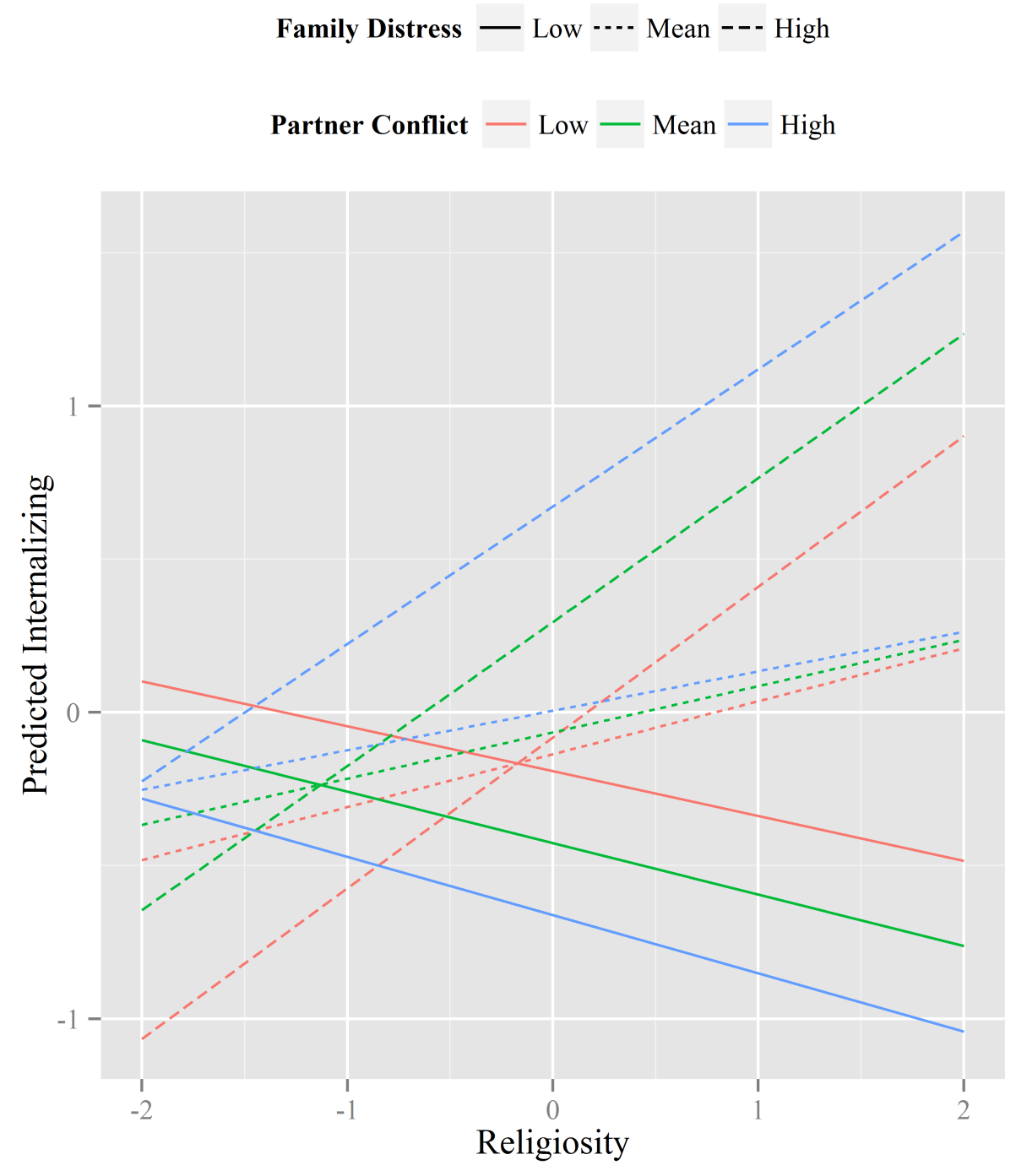

Figure 1. Internalizing Exploratory Results. 


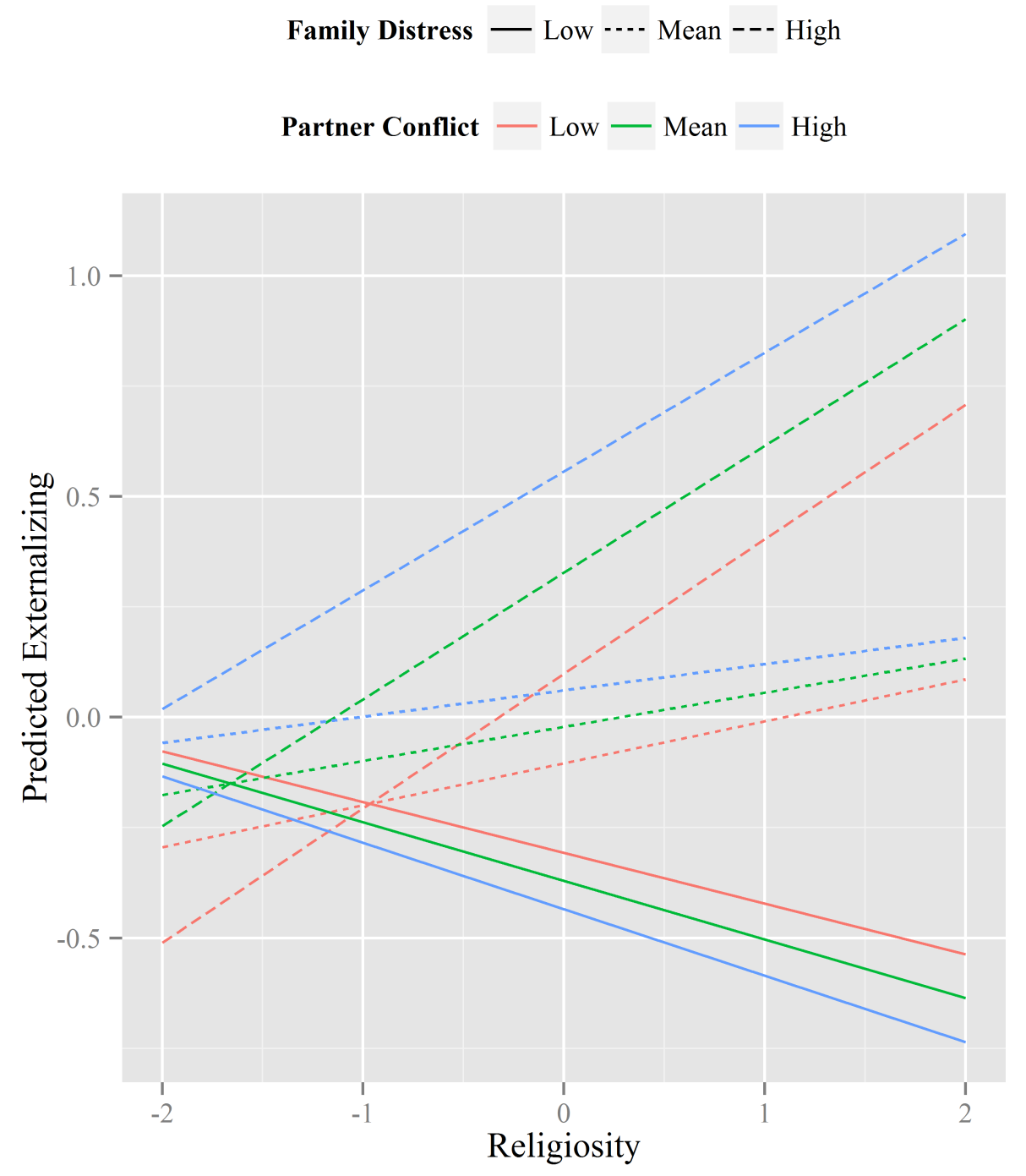

Figure 2. Externalizing Exploratory Results.

Due to low numbers of participants in each religious group (see Table 1), I was unable to conduct analyses separately for each individual religion. I was, however, able to conduct the analyses on the subset of Christians in the sample. Since Christians were the predominant group in my sample and much of the extant literature is based on Christian populations, I also conducted similar analyses solely on the Christian sample $(n=128)$. When standardized scores for religiosity, interparental conflict, and the interaction term were included as predictors for internalizing behaviors, a marginally significant 
interaction emerged $(\beta=-.19, t(124)=-1.81, p=.072)$. See Table 9. A similar trend was seen when standardized scores for religiosity, interparental conflict, and the interaction term were included as predictors for externalizing behaviors, but there was no evidence of a significant interaction, as shown in Table 10. When the interaction term was removed, interparental conflict again emerged as a significant predictor; however, there was no evidence that religiosity predicted children's externalizing behavior.

Table 9

Christian Subsample Analyses for Internalizing Behaviors

\begin{tabular}{lccc}
\hline Variables & $\beta$ & $\sigma_{\beta}$ & $t$ \\
\hline Frequency/Severity of Interparental & $.22^{*}$ & .09 & 2.46 \\
Conflict & -.14 & .11 & -1.33 \\
Religiosity & $-.19 \dagger$ & .10 & -1.81 \\
Interparental Conflict $\times$ Religiosity & & &
\end{tabular}

Table 10

Christian Subsample Analyses for Externalizing Behaviors

\begin{tabular}{lccc}
\hline Variables & $\beta$ & $\sigma_{\beta}$ & \multicolumn{1}{c}{$t$} \\
\hline Frequency/Severity of Interparental Conflict & $.18^{*}$ & .09 & 2.05 \\
Religiosity & -.09 & .10 & -0.90 \\
Interparental Conflict $\times$ Religiosity & -.15 & .10 & -1.41 \\
\hline$* p<.05$ & & &
\end{tabular}




\section{CHAPTER V}

\section{SUMMARY, CONCLUSIONS, AND RECOMMENDATIONS}

\section{Summary of the Research Problem, Methods, and Findings}

The goal of this study was to test the hypothesis that parental religiosity

moderates the relation between interparental conflict and children's internalizing behaviors and that parental religiosity also moderates the relation between interparental conflict and children's externalizing behaviors, controlling for family distress. It was expected that increased religiosity would be associated with decreased internalizing and externalizing behavior. I also intended to explore how these results did or did not differ across different religious groups. There was insufficient evidence for either model to be determined to be significant.

Exploratory analysis yielded interesting information. When family distress was included as a predictor, religiosity was a significant predictor for internalizing and externalizing behaviors at high levels of family distress, such that higher levels of religiosity were actually associated with higher levels of internalizing and externalizing behaviors. The findings were more pronounced for internalizing behaviors than for externalizing behaviors. Sample sizes were not large enough in groups besides Christians to determine if the hypotheses held were supported within each other religious group. However, I conducted cross-product multiple regression analysis on just the Christian 
sample in order to test the hypotheses within this sample. There was evidence for a marginally significant interaction in the internalizing model, but no evidence for a significant interaction in the externalizing model.

\section{Implications}

Although there was no evidence in this study to suggest that parent religiosity acts as a resilience factor, there was evidence that, at high levels of family distress, parent religiosity might be a risk factor for internalizing and externalizing behaviors. This seems to contradict most of the current literature regarding religiosity. However, one key difference between my research and the literature is that I am looking at children under the age of 12 . Nearly all extant studies look at the influence of individual religiosity an adults or older children. Those that do look at the influence of parent religiosity do so primarily on older children as well (e.g. Schreiber 2013). It may be that individual religiosity would be a resilience factor for children, if we were better able to measure the religiosity of young children.

There has been some, but minimal research in the literature to suggest that some aspects of parental religiosity may be related to increased internalizing or externalizing behaviors, particularly in younger children. Although Petts (2011) found that weekly religious service attendance by both parents was associated with lower externalizing behaviors in their children under age 6 , the study found that having parents with strict religious beliefs, was actually associated with higher levels of internalizing behavior in children. The study measured "strict religious beliefs" by evaluating the parent's adherence to one particular religious tenet that they deemed central to that particular 
faith. For example, if Protestants believed that the Bible should be taken literally or if Catholics believed that the Eucharist was the literal body and blood of Jesus Christ (Petts, 2011). Although this measure of religiosity, the BMMRS, is not attempting to measure strictness of religious belief, it is possible that parent attendance at religious services might be associated with resilience, whereas parent religion measured more broadly (whether by strictness of belief as in Petts or multi-dimensionally as in the BMMRS) might be associated with risk.

It is also possible that religiosity is not a risk factor in and of itself, but it is correlated with a risk factor. Another explanation could be presented that parent religiosity increases in response to family distress, as do children's internalizing and externalizing behavior. Indeed, many adults report using religion to cope with stressful situations (e.g. Pargament, Tarakeshwar, Ellison, \& Wulff, 2001; Rammohan, Rao, \& Subbakrishna, 2002). Thus, it is possible that the higher religiosity in families with higher distress indicates the use of religion as a means of coping rather than religiosity causing increased difficulties.

Another possibility is that a larger sample size including more participants of other religious groups besides Christianity may be necessary in order to have sufficient power to demonstrate significant evidence for the hypothesized models. This possibility would be consistent with the many studies that have found that religiosity functions as a moderator between family-level risk factors and individual behavioral outcomes (e.g. Davis \& Epkins, 2009; Fowler, Ahmed, Tompsett, Jozefowicz-Simbeni, \& Toro, 2008; Hair et al., 2008; Wills et al., 2003). Respondents were not representative of the U.S. 
population, with regard to religious group. Buddhists, Hindus, Jews, and Muslims were oversampled, whereas those unaffiliated with any religion were undersampled. It's possible that undersampling those unaffiliated meant that the sample as a whole was more religious than the general population. If this were the case, perhaps capturing a broader degree of religiosity, combined with simply a larger sample size, would provide sufficient power.

Although this study did not find sufficient evidence to support the hypothesis, it does add information to the literature. I am unaware of any studies regarding parental religion as a moderating factor in children as young as five. Few studies consider the religious environment of young children. Since this study has indicated evidence to support the fact that, at high levels of family distress, religiosity could be related to increased childhood internalizing and externalizing behaviors, it has provided evidence to suggest the importance of considering a child's religious environment.

This research also suggests that a family's religious environment could provide important clinical information for therapists of young children. This research provides evidence to suggest that practitioners should ask about the child's religious environment in the assessment of even very young children seeking mental health services. In families with significant distress, practitioners might tentatively consider parent religiosity as a risk factor for higher internalizing or externalizing behaviors. Further research is needed in order for practitioners to be able to draw firmer conclusions, but this research supports the fact that religion should be considered in the assessment of even very young children. 


\section{Limitations}

Even though this study provided important insight into a number of different questions, there were a few noteworthy limitations. First and foremost, the study sample was primarily white and Christian. Second (and related), the study was based on a convenience sample and is self-selected, which could introduce biases, such as a sample that is more religious than the population. Another limitation is that all data was only obtained from one informant. Although partners have been shown to correlate strongly on the measure of interparental conflict, both partners' perspectives on the interparental conflict would have been useful information (Kerig, 1996). Further, parents' religiosity and religion can often be very different and this would not be reflected in the current data (Murphy, 2015). What's more, the data from this study indicated that fathers were more likely to report externalizing behaviors in their children than mothers so having two parents' perspectives could provide us with different information about the children's behaviors. Another potential limitation is that the highly sensitive nature of many of the questions, particularly those regarding religion and child behaviors, may have introduced social desirability bias. Although I attempted to control for this by including the measures in reverse order in the two different versions, I did not measure social desirability directly, so it is possible that this influenced responses.

A final limitation concerns the usefulness of the measures themselves. The measure for frequency and severity of interparental conflict was quite short and demonstrated lower reliability in this sample than the other measures. Using a broader subscale of the Conflicts and Problem-Solving Scale might have provided more 
information. The religiosity measure is also a concern. It was designed to be a broad measure of religious experience. In some ways, this breadth is a positive aspect, because it allows researchers to capture religiosity beyond simply attendance at religious services or one-item questions such as "How religious are you?" In other ways, though, it may be that the religiosity measure was too broad, including aspects of religiosity that may be salient for the individual parents, but would not influence the child's behaviors. In trying to capture all aspects of religiosity, this measure may have obscured important individual aspects of religiosity, such as religious coping, religious support, and even religious service attendance.

\section{Recommendations for Future Research}

Future research should be conducted with a larger sample size, particularly in religious groups besides Christian as well as non-religious people, in order to determine if a study with larger power is needed to support the hypothesized model or if the current findings become more pronounced. Future research should also include measurements of social desirability bias in order to determine its potential influence on parents' responses. In order to better understand the significance of the findings of this study, future research might also consider analyzing the subscales within the religiosity measure, such as religious coping or spiritual support subscales. Although research regarding these subscales with parents is rare, Tarakeshwar and Pargament (2001) studied religious coping in 45 parents of children with autism. They found that positive religious coping (such as seeking spiritual support and finding positive meaning in suffering) was significantly correlated with self-reported growth due to the stressors related to having a 
child with autism. By contrast, self-reported religiosity (determined via one item) was not significantly correlated with stress-related growth.

Rammohan, Rao, and Subbakrishna (2002) conducted another study regarding using religious coping in 60 people caring for a family member with schizophrenia. In this instance, religious coping did not correlate with their outcome variable of psychological well being. By contrast, strength of religious belief did correlate significantly with the psychological well being of these caregivers. These results are mixed regarding religious coping in particular, but they do emphasize that different aspects of religiosity may be related to different outcome variables. Thus, they suggest that a narrower perspective may provide more information regarding the mechanisms behind the results in this study.

Further research in religion as a family-level factor might also encourage the development of a measure specifically for family religiosity or for child religiosity. In this regard, a qualitative or mixed-methods approach might be ideal in order to further determine what aspects of religiosity are salient either at the family level or to children. Interviews with children could elicit information regarding how the religious environment of the family influences them, thus providing data for the development of new and better measures. Like all other research examining religion in children, qualitative studies in this area are rare. Ní Raghallaigh and Gilligan (2010) used a qualitative study to determine how adolescents cope with the stressors of immigration in 32 adolescents seeking asylum. Their research found that religious coping was a common theme among adolescents and that it facilitated such coping strategies as maintaining a 
positive outlook and maintaining continuity. Thus, qualitative studies emphasize the importance of religion in young people's lives, even when it is not the primary focus of the study.

Some qualitative research has been conducted specifically on children's religious coping. Pendleton, Cavalli, Pargament, and Nasr (2002) studied 23 children with cystic fibrosis ages 5 to 12 years old in order to gain more information on how they viewed religious coping. They used interviews with parents and children and analysis of themes in children's drawings. They found 11 central patterns within children's spiritual and religious coping: declarative religious coping (in which someone asks God to be healed and expects to be automatically healed), petitionary religious coping (someone asks God to be healed and may or may not be), collaborative religious coping (child and God work together to cope), belief in God's support, belief in God's intervention, belief that God is irrelevant, spiritual social support, ritual response (that is, the child participates in more religious rituals to feel better), benevolent religious reappraisal (finding positive religious meaning in an illness), punishing religious appraisal (finding negative religious meaning in an illness such as punishment for sins), and discontent with God. Future research might use similar methods in all children or children with interparental conflict in particular to determine if these coping patterns in children are universal as well as how children experience religion outside of the domain of coping.

\section{Conclusion}

The research presented here did not provide evidence to support the hypothesis that parental religiosity moderates the relation between interparental conflict and 
children's internalizing and externalizing behaviors such that higher religiosity correlates with lower children's internalizing and externalizing behaviors. However, in families with high distress, there is evidence that religiosity may moderate the relationship between partner conflict and child internalizing and externalizing behavior such that religiosity was related to higher problem behavior. Although this was not the anticipated result, this research provides some evidence to indicate that family-level religion should be considered when assessing a child's risk and resilience. These results also emphasize, in a broader sense, how important family-level factors are to "half the art of living." Truly, if we in the field of psychology are interested in bettering the outcomes of children facing adversity, further research in religion is necessary. 


\section{REFERENCES}

Abu-Rayya, M. H., \& Abu-Rayya, H. M. (2009). Ethnic identification, religious identity, and psychological well-being among Muslim and Christian Palestinians in Israel. Mental Health, Religion \& Culture, 12(2), 147-155.

Abdel-Khalek, A. M. (2007). Religiosity, happiness, health, and psychopathology in a probability sample of Muslim adolescents. Mental Health, Religion \& Culture, 10(6), 571-583.

Abdel-Khalek, A. M. (2009). Religiosity, subjective well-being, and depression in Saudi children and adolescents. Mental Health, Religion \& Culture, 12(8), 803-815.

Abdel-Khalek, A. M., \& Lester, D. (2007). Religiosity, health, and psychopathology in two cultures: Kuwait and USA. Mental Health, Religion \& Culture, 10(5), 537550 .

Ahmed, S. R., Fowler, P. J., \& Toro, P. A. (2011). Family, public and private religiousness and psychological well-being over time in at-risk adolescents. Mental Health, Religion \& Culture, 14(4), 393-408.

Ai, A. L., Peterson, C., \& Huang, B. (2003). The effects of religious-spiritual coping on positive attitudes of adult Muslim refugees from Kosovo and Bosnia. The International Journal for the Psychology of Religion, 13(1), 29-47.

Aiken, L. S., \& West, S. G. (1991). Multiple regression: Testing and interpreting interactions. Newbury Park, CA: Sage Publications.

Anderson, S. A., \& Sabatelli, R. M. (1990). Differentiating differentiation and individuation: Conceptual and operation challenges. American Journal of Family Therapy, 18(1), 32-50. doi:10.1080/01926189008250790

Andrews, C. R., \& Marotta, S. A. (2005). Spirituality and coping among grieving children: A preliminary study. Counseling and Values, 50, 38-50.

Ano, G. G., \& Vasconcelles, E. B. (2005). Religious coping and psychological adjustment to stress: A meta-analysis. J Clin Psychol, 61, 461-480.

Bader, C. D., \& Desmond, S. A. (2006). Do as I say and as I do: The effects of consistent parental beliefs and behaviors upon religious transmission. Sociology of Religion, 67(3), 313-329. 
Bagby, I., Perl, P. M., \& Froehle, B. T. (2001). The mosque in America: A national portrait. Retrieved from Council on American-Islamic Relations website: https://www.cair.com/images/pdf/The-American-mosque-2001.pdf

Bastide, D. (1987). Children and religion: Age and understanding. In Religious education 5-12 (pp. 16-23). Retrieved from https://books.google.com/books?id=pfXNUxebv0C\&printsec $=$ frontcover\&source $=$ gbs_ge_summary_r\&cad $=0 \# v=$ onepa ge\&q\&f=false

Bavelas, J. B., \& Segal, L. (1982). Family Systems Theory: Background and Implications. Journal of Communication, 32, 89-107.

Bentler, P. M. (2006). EQS 6 Structural Equations Program Manual. Encino, CA: Multivariate Software, Inc.

Bergin, A. E., Masters, K. S., \& Richards, P. S. (1987). Religiousness and mental health reconsidered: A study of an intrinsically religious sample. Journal of Counseling Psychology, 34(2), 197-204.

Black, K., \& Lobo, M. (2008). A conceptual review of family resilience factors. Journal of Family Nursing, 14(1), 33-55.

Buehler, C., Krishnakumar, A., Stone, G., Anthony, C., Pemberton, C., Gerard, J., \& Barber, B.K. (1998). Interparental conflict styles and youth problem behaviors: A two-sample replication study. Journal of Marriage and the Family, 60(1), 119132.

Braam, A. W., Van Den Eeden, P., Prince, M. J., Beekman, A. T. F., Kivela, S., Lawlor, B. A., Birkhofer, A., Fuhrer, R., Lobo, A., Magnusson, H., Mann, A. H., Meller, I., Roelands, M., Skoog, I., Turrina, C., \& Copeland, J. R. M. (2001). Religion as a cross-cultural determinant of depression in elderly Europeans: Results from the EURODEP collaboration. Psychological Medicine, 31, 803-814.

Britt, G. C. (1995, April). Children's coping with everyday stressful situations: The role played by religion. Poster presented at The 61st biennial meeting of the society for research in child development, Indianapolis, IN.

Bullock, M., Nadeau, L., \& Renaud, J. (2012). Spirituality and religion in youth suicide attempters' trajectories of mental health service utilization: The year before a suicide attempt. J Can Acad Child Adolesc Psychiatry, 21(3), 186-193.

Caputo, R. K. (2004). Parent religiosity, family processes, and adolescent outcomes. Families in Society: The Journal of Contemporary Social Services, 85(4), 495510.

Carothers Bert, S. (2011). The influence of religiosity and spirituality on adolescent mothers and their teenage children. $J$ Youth Adolescence, 40, 72-84. 
Carleton, R. A., Esparza, P., Thaxter, P. J., \& Grant, K. E. (2008). Stress, religious coping resources, and depressive symptoms in an urban adolescent sample. Journal for the Scientific Study of Religion, 47(1), 113-121.

Carpenter, T. P., Laney, T., \& Mezulis, A. (2012). Religious coping, stress, and depressive symptoms among adolescents: A prospective study. Psychology of Religion and Spirituality, 4(1), 19-30.

Cavalletti, S. (1983). The religious potential of the child. New York, NY: Paulist Press.

Chitwood, D. D., Weiss, M. L., \& Leukefeld, C. G. (2008). A systematic review of recent literature on religiosity and substance use. Journal of Drug Issues, 38, 653-688.

Christian, M. D., \& Barbarin, O. A. (2001). Cultural resources and psychological adjustment of African American children: Effects of spirituality and racial attribution. Journal of Black Psychology, 27(1), 43-63.

Chu, D. C., \& Sung, H. (2009). Racial differences in desistance from substance abuse: The impact of religious involvement on recovery. International Journal of Offender Therapy and Comparative Criminology, 53(6), 696-716.

Cochrane, R., \& Bal, S. (1990). The drinking habits of Sikh, Hindu, Muslim, and white men in the West Midlands: A community survey. British Journal of Addiction, $85,759-769$.

Cohen, A. B., \& Hall, D. E. (2009). Existential beliefs, social satisfaction, and well-being among Catholic, Jewish, and Protestant older adults. The International Journal for the Psychology of Religion, 19, 39-54.

Cohen, A. B., Siegel, J. I., \& Rozin, P. (2003). Faith versus practice: Different bases for religiosity judgements by Jews and Protestants. The International Journal for the Psychology of Religion, 33(2), 287-295.

Cohen, C. I., Jimenez, C., \& Mittal, S. (2010). The role of religion in the well-being of older adults with schizophrenia. Psychiatric Services, 61(9), 917-922.

Condly, S. J. (2006). Resilience in children: A review of literature with implications for education. Urban Education, 41(3), 211-236.

Cotton, S., Grossoehme, D., Rosenthal, S. L., McGrady, M. E., Humenay Roberts, Y., Hines, J., Yi, M. S., \& Tsevat, J. (2009). Religious/spiritual coping in adolescents with sickle cell disease: A pilot study. J Pediatr Hematol Oncol, 31(5), 313-318.

Cox, C. E., Kotch, J. B., \& Everson, M. D. (2003). A longitudinal study of modifying influences in the relationship between domestic violence and child maltreatment. Journal of Family Violence, 18(1), 5-17. 
Crawford, E., Wright, M. O., \& Masten, A. S. (2006). Resilience and spirituality in youth. In E. C. Roehlkepartain, P. E. King, L. M. Wagener, \& P. L. Benson (Ed.), The handbook of spiritual development in childhood and adolescence (pp. 355370). Thousand Oaks, CA: SAGE Publications.

Crijnen, A. A., Achenbach, T. M., \& Verhulst, F. C. (1997). Comparisons of problems reported by parents of children in 12 cultures: Total problems, externalizing, and internalizing. Journal of The American Academy of Child and Adolescent Psychiatry, 36, 1269-1277. doi:10.1097/00004583-199709000-00020

Davis, K. A., \& Epkins, C. C. (2009). Do private religious practices moderate the relation between family conflict and preadolescents' depression and anxiety symptoms?. The Journal of Early Adolescence, 29, 693-717.

Dervic, K., Oquendo, M. A., Grunebaum, M. F., Ellis, S., Burke, A. K., \& Mann, J. J. (2004). Religious affiliation and suicide attempt. Am J Psychiatry, 161, 23032308 .

Desrosiers, A., \& Miller, L. (2007). Relational spirituality and depression in adolescent girls. Journal of Clinical Psychology, 63, 1021-1037. doi:10.1002/jclp.20409

Dew, R. E., Daniel, S. S., Goldston, D. B., McCall, W. V., Kuchibhatla, M., Schleifer, C., ... Koenig, H. G. (2010). A prospective study of religion/spirituality and depressive symptoms among adolescent psychiatric patients. Journal of Affective Disorders, 120, 149-157. doi:10.1016/j.jad.2009.04.029

Dumas, J. E., \& Nissley-Tsiopinis, J. (2006). Sanctification of parenting, and positive and negative religious coping as predictors of parental and child functioning. The International Journal for the Psychology of Religion, 16(4), 289-310.

Dyslin, C. W., \& Thomsen, C. J. (2005). Religiosity and risk of perpetrating child physical abuse: An empirical investigation. Journal of Psychology and Theology, 33(4), 291-298. Retrieved from http://journals.biola.edu/jpt

Eskin, M. (2004). The effects of religious versus secular education on suicide ideation and suicidal attitudes in adolescents in turkey. Soc Psychiatry Psychiatr Epidemiol, 39, 536-642.

Epstein, N. B., Baldwin, L. M., \& Bishop, D. S. (1983). The McMaster Family Assessment Device*. Journal of marital and family therapy, 9(2), 171-180.

Fallot, R. D., \& Heckman, J. P. (2005). Religious/spiritual coping among women trauma survivors with mental health and substance use disorders. Journal of Behavioral Health Services \& Research, 32(2), 215-226. 
Farmer, A. Y., Sinha, J. W., \& Gill, E. (2008). The effects of family religiosity, parental limit-setting, and monitoring on adolescent substance use. Journal of Ethnicity in Substance Abuse, 7(4), 428-450.

Fergusson, D. M., \& Horwood, L. J. (2003). Resilience to childhood adversity: Results of a 21 year study. In S. S. Luthar (Ed.), Resilience and vulnerability: Adaptation in the context of childhood adversities (pp. 130-155). Cambridge, U.K: Cambridge University Press.

Fetzer Institute. National Institute on Aging, (1999). Multidimensional measurement of religiousness/spirituality for use in health research: A report of the fetzer institute/national institute on aging work group. Kalamazoo, MI: John E. Fetzer Institute.

Fisher, K., Newbold, K. B., Eyles, J., \& Elliot, S. (2013). Mental health in a Canadian Old Order Mennonite community. Health, 5, 538-556.

Flannelly, L. T., \& Inouye, J. (2001). Relationships of religion, health status, and socioeconomic status to the quality of life of individuals who are hiv positive. Issues in Mental Health Nursing, 22, 253-272.

Francis, L. J., \& Gibson, H. M. (1993). Parental influence and adolescent religiosity: A study of church attendance and attitude toward Christianity among adolescents 11 to 12 and 15 to 16 years old. The International Journal for the Psychology of Religion, 3(4), 241-253.

Francis, L. J., \& Kaldor, P. (2002). The relationship between psychological well-being and Christian faith and practice in an Australian population sample. Journal for the Scientific Study of Religion, 41(1), 179-184.

Frazier, C., Mintz, L. B., \& Mobley, M. (2005). A multidimensional look at religious involvement and psychological well-being among urban elderly African Americans. Journal of Counseling Psychology, 52(4), 583-590.

French, D. C., Eisenberg, N., Vaughn, J., Purwono, U., \& Suryanti, T. A. (2008). Religious involvement and the social competence and adjustment of Indonesian Muslim adolescents. Developmental Psychology, 44(2), 597-611.

Fry, P. S. (2000). Religious involvement, spirituality and personal meaning for life: Existential predictors of psychological wellbeing in community-residing and institutional care elders. Aging \& Mental Health, 4(4), 375-387.

Fowler, P. J., Ahmed, S. R., Tompsett, C. J., Jozefowicz-Simbeni, D. M. H., \& Toro, P. A. (2008). Community violence and externalizing problems: Moderating effects of race and religiosity in emerging adulthood. J Community Psychol, 36(7), 835850 . 
Goeke-Morey, M. C., Cairns, E., Merrilees, C. E., Schermerhorn, A. C., Shirlow, P., \& Cummings, E. M. (2013). Maternal religiosity, family resources and stressors, and parent-child attachment security in Northern Ireland. Social Development, 22(1), $19-37$.

Gonzales, N. A., Pitts, S. C., Hill, N. E., \& Roosa, M. W. (2000). A mediational model of the impact of interparental conflict on child adjustment in a multiethnic, lowincome sample. Journal of Family Psychology, 14(3), 365-379.

Green, M., \& Elliott, M. (2010). Religion, health, and psychological well-being. Journal of Religion \& Health, 49, 149-163.

Greening, L., \& Stoppelbein, L. (2002). Religiosity, attributional style, and social support as psychosocial buffers for African American and white adolescents? Perceived risk for suicide. Suicide and Life-threatening Behavior, 32(4), 404-417.

Hair, E. C., Moore, K. A., Hadley, A., \& Sidorowicz, K. (2008). Family religiosity and mental health in young adults. Bethesda, MD: Child Trends.

Hilton, S. C., Fellingham, G. W., \& Lyon, J. L. (2002). Suicide rates and religious commitment in young adult males in Utah. American Journal of Epidemiology, 155(5), 413-419.

Holder, M. D., Coleman, B., \& Wallace, J. M. (2010). Spirituality, religiousness, and happiness in children aged 8-12 years. Journal of Happiness Studies, 11, 131150 .

Hood, R. W., Hill, P. C., \& Spilka, B. (2009). The psychology of religion: An empirical approach (4th ed.). New York: Guilford Press.

Houltberg, B. J., Henry, C. S., Merten, M. J., \& Robinson, L. C. (2011). Adolescents' perceptions of family connectedness, intrinsic religiosity and depressed mood. Journal of Child and Family Studies, 20, 111-119.

Huesmann, L. R., Dubow, E. F., \& Boxer, P. (2011). The effect of religious participation on aggression over one's lifetime and across generations. In J. Forgas, A. Kruglanski \& K. Williams (Eds.), The Psychology of Social Conflict and Aggression (pp. 299-320). New York, NY: Psychology Press.

Huculak, S., \& McLennan, J. D. (2010). "The Lord in my shepherd": Examining spirituality as a protection against mental health problems in youth exposed to violence in Brazil. Mental Health, Religion \& Culture, 5, 467-484.

Hsu, P. H., Krägeloh, C. U., Shepherd, D., \& Billington, R. (2009). Religion/spirituality and quality of life of international tertiary students in New Zealand: an exploratory study. Mental Health, Religion \& Culture, 12(4), 385-399. 
Idler, E. L., Musick, M. A., Ellison, C. G., George, L. K., Krause, N., Ory, M. G., . . . Williams, D. R. (2003). Measuring Multiple Dimensions of Religion and Spirituality for Health Research: Conceptual Background and Findings from the 1998 General Social Survey. Research on Aging, 25(4), 327-365.

doi:10.1177/0164027503025004001

Ingoldsby, E. M., Shaw, D. S., Owens, E. B., \& Winslow, E. B. (1999). A longitudinal study of interparental conflict, emotional and behavioral reactivity, and preschoolers' adjustment problems among low-income families. Journal of Abnormal Child Psychology, 27(5), 343-356.

Jackson, L. J., Roller White, C., O'Brien, K., DiLorenzo, P., Cathcart, E., Wolf, M., Bruskas, D., Pecora, P.J., Nix-Early, V., \& Cabrera, J. (2010). Exploring spirituality among youth in foster care: Findings from the Casey Field Office Mental Health Study. Child and Family Social Work, 15, 107-117.

Jackson, S., Thompson, R. A., Christiansen, E. H., Colman, R. A., Wyatt, J., Buckendahl, C. W., .. . Peterson, R. (1999). Predicting abuse-prone parental attitudes and discipline practices in a nationally representative sample. Child Abuse \& Neglect, 23(1), 15-29. doi:10.1016/S0145-2134(98)00108-2

Jacobs, M., Miller, L., Wickramaratne, P., Gameroff, M., \& Weissman, M. M. (2012). Family religion and psychopathology in children of depressed mothers: Ten-year follow-up. Journal of Affect Disorders, 136(3), 320-327.

Jang, J., Kim, S., Kim, S., Kim, J., Park, M., Yoon, J., . . Yoon, J. (2013). Religiosity, depression, and quality of life in Korean patients with breast cancer: a 1-year prospective longitudinal study. Psycho-Oncology, 22, 922-929.

Jellinek, M., Murphy, J., Robinson, J., Feins, A., Lamb, S., \& Fenton, T. (1988). Pediatric symptom checklist: Screening school-age children for psychosocial dysfunction. Journal of Pediatrics, 112(2), 201-209.

Johnstone, B., McCormack, G., Yoon, D. P., \& Smith, M. L. (2012). Convergent/ divergent validity of the brief multidimensional measure of religiousness/spirituality: Empirical support for emotional connectedness as a "spiritual" construct. J Relig Health, 51, 529-541.

Johnstone, B., Yoon, D. P., Franklin, K. L., Schopp, L., \& Hinkebein, J. (2009). Reconceptualizing the factor structure of the brief multidimensional measure of religiousness/spirituality. Journal of Religion \& Health, 48, 146-163.

June, A., Segal, D. L., Coolidge, F. L., \& Klebe, K. (2009). Religiousness, social support and reasons for living in African American and European American older adults: An exploratory study. Aging \& Mental Health, 13(5), 753-760. doi:10.1080/13607860902918215 
Kabacoff, R. I., Miller, I. W., Bishop, D. S., Epstein, N. B., \& Keitner, G. I. (1990). A psychometric study of the McMaster family assessment device in psychiatric, medical, and nonclinical samples. Journal of Family Psychology, 3(4), 431-439.

Kedem, P. (1995). Dimensions of Jewish religiosity. In S. A. Deshen, C. S. Liebman, \& M. Shokeid (Eds.), Israeli Judaism: The sociology of religion in Israel (pp. 3362). New Brunswick, N.J: Transaction Publishers.

Kendler, K. S., Gardner, C. O., \& Prescott, C. A. (1997). Religion, psychopathology, and substance use and abuse: A multimeasure, genetic-epidemiologic study. Am J Psychiatry, 154, 322-329.

Kerig, P. K. (1996). Assessing the links between interparental conflict and child adjustment: The conflicts and problem-solving scales. Journal of Family Psychology, 10(4), 454-473.

Kerig, P. K. (1998). Gender and Appraisals as Mediators of Adjustment in Children Exposed to Interparental Violence. Journal of Family Violence, 13(4), 345-363.

Kim, J., McCullough, M. E., \& Cicchetti, D. (2009). Parents' and children's religiosity and child behavioral adjustment among maltreated and nonmaltreated children. $J$ Child Fam Stud, 18(5), 594-605.

Kim, S., \& Esquivel, G. B. (2011). Adolescent spirituality and resilience: Theory, research, and educational practices. Psychology in the Schools, 48(7), 755-765.

King, J. E., \& Crowther, M. R. (2004). The measurement of religiosity and spirituality: Examples and issues from psychology. Journal of Organizational Change Management, 17(1), 83-101.

Koenig, H. G. (2009). Research on religion, spirituality, and mental health: A review. Can J Psychiatry, 54(5), 283-291.

Krejci, M. J., Thompson, K. M., Simonich, H., Crosby, R. D., Donaldson, M. A., Wonderlich, S. A., \& Mitchell, J. E. (2004). Sexual trauma, spirituality, and psychopathology. Journal of Child Sexual Abuse, 13(2), 85-103.

Lees, J. (2014). Secrets of resilient people: 50 strategies to be strong. New York City, NY: McGraw-Hill.

Leonard, K. C., Cook, K. V., Boyatzis, C. J., Kimball, C. N., \& Flanagan, K. S. (2013). Parent-child dynamics and emerging adult religiosity: Attachment, parental beliefs, and faith support. Psychology of Religion and Spirituality, 5(1), 5-14.

Levin, J. (2013). Religious behavior, health, and well-being among Israeli Jews: Findings from the European Social Survey. Psychology of Religion and Spirituality, 5, $272-282$. 
Loewenthal, K. M. (2000). The psychology of religion: A short introduction. Oxford, England: Oneworld Publications.

Loue, S., \& Sajatovic, M. (2006). Spirituality, coping, and HIV risk and prevention in a sample of severely mentally ill Puerto Rican women. Journal of Urban Health: Bulletin of the New York Academy of Medicine, 83(6), 1168-1182.

Lustig, S. L., Kia-Keating, M., Grant Knight, W., Geltman, P., Ellis, H., Kinzie, J. D., Keane, T., \& Saxe, G. N. (2004). Review of child and adolescent refugee mental health. J. Am. Acad. Child Adolesc. Psychiatry, 43(1), 24-36.

Luthar, S. S., Cicchetti, D., \& Becker, B. (2000). The construct of resilience: A critical evaluation and guidelines for future work. Child Development, 71(3), 543-562.

Maltby, J., Lewis, C. A., \& Day, L. (1999). Religious orientation and psychological wellbeing: The role of the frequency of personal prayer. British Journal of Health Psychology, 4, 363-378.

Maselko, J., Hayward, R. D., Hanlon, A., Buka, S., \& Meador, K. (2012). Religious service attendance and major depression: A case of reverse causality?. Am J Epidemiol, 175(6), 576-583.

Masten, A. S. (2001). Ordinary magic: Resilience processes in development. American Psychologist, 56(3), 227-238.

Masten, A. S. (2011). Resilience in children threatened by extreme adversity: Frameworks for research, practice, and translational energy. Development and Psychopathology, 23, 493-506.

Mathai, J., \& North, A. (2003). Spiritual history of parents of children attending a child and adolescent mental health service. Australasian Psychiatry, 11(2), 172-174. doi:10.1046/j.1039-8562.2003.00511.x

Meltzer, H. I., Dogra, N., Vostanis, P., \& Ford, T. (2011). Religiosity and the mental health of adolescents in Great Britain. Mental Health, Religion \& Culture, 14(7), 703-713.

Miller, L., Wickramaratne, P., Gameroff, M. J., Sage, M., Tenke, C. E., \& Weissman, M. M. (2012). Religiosity and major depression in adults at high risk: a ten-year prospective study. Am J Psychiatry, 169, 89-94.

Mokuau, N., Hishinuma, E., \& Nishimura, S. (2001). Validating a measure of religiousness/spirituality for native Hawaiians. Pacific Health Dialogue, 8(2), $407-416$.

Moreira-Almeida, A., Lotufo Neto, F., \& Koenig, H. G. (2006). Religiousness and mental health: A review. Rev Bras Psiquiatr, 28(3), 242-250. 
Morris, G. J. \& McAdie, T. (2009). Are personality, well-being and death anxiety related to religious affiliation? Mental Health, Religion \& Culture, 12(2), 115-120.

Murphy, C. (2015). Interfaith marriage is common in U.S., particularly among the recently wed. Retrieved from Pew Research Center website: http://www.pewresearch.org/fact-tank/2015/06/02/interfaith-marriage/

Murphy, J. M., \& Jellinek, M. (1985). Development of a brief psychosocial screening instrument for pediatric practice: Final report (Contract No. 84M0213612). Rockville, MD: Department of Health and Human Services, Alcohol, Drug Abuse, and Mental Health Administration, Division of Biometry and Applied Sciences.

Murphy, J. M., \& Jellinek, M. (2010). Screening for psychosocial dysfunction in economically disadvantaged and minority group children: Further validation of the pediatric symptom checklist. American Journal of Orthopsychiatry, 58(3), $450-456$.

Ní Raghallaigh, M., \& Gilligan, R. (2010). Active survival in the lives of unaccompanied minors: Coping strategies, resilience, and the relevance of religion. Child and Family Social Work, 15, 226-237.

Nye, W. C., \& Carlson, J. S. (1984). The development of the concept of God in children. The Journal of Genetic Psychology, 145, 137-142. Retrieved from http://www.tandfonline.com/loi/vgnt20\#.VdD9pK1dUww

Okagaki, L., \& Bevis, C. (1999). Transmission of religious values: Relations between parents' and daughters' beliefs. The Journal of Genetic Psychology, 160(3), 303318.

Pargament, K. I., Tarakeshwar, N., Ellison, C. G., \& Wulff, K. M. (2001). Religious Coping Among the Religious: The Relationships Between Religious Coping and Well-Being in a National Sample of Presbyterian Clergy, Elders, and Members. Journal for the Scientific Study of Religion, 40(3), 497-515.

Pearce, M. J., Jones, S. M., Schwab-Stone, M. E., \& Ruchkin, V. (2003). The protective effects of religiousness and parent involvement on the development of conduct problems among youth exposed to violence. Child Development, 74(6), 16821696.

Pearce, M. J., Little, T. D., \& Perez, J. E. (2003). Religiousness and depressive symptoms among adolescents. Journal of Clinical Child and Adolescent Psychology, 32(2), 267-276.

Pendleton, S. M., Cavalli, K. S., Pargament, K. I., \& Nasr, S. Z. (2002).

Religious/spiritual coping in childhood cystic fibrosis: A qualitative study.

Pediatrics, 109(1), 165-173. 
Petts, R. J. (2011). Parental religiosity, religious homogamy, and young children's wellbeing. Sociology of Religion, 72(4), 389-414.

Pew Forum on Religion \& Public Life. (2008). U.S. religious landscape survey: Religious affiliation. Washington, DC: Pew Forum Web Publishing and Communications.

Potter, P. B. (2003). Belief in control: Regulation of religion in China. In D. L. Overmyer (Ed.), Religion in China today (pp. 11-31). Cambridge, U.K.: Cambridge University Press.

Proffitt, D., Cann, A., Calhoun, L. G., \& Tedeschi, R. G. (2007). Judeo-Christian clergy and personal crisis: Religion, posttraumatic growth and well being. Journal of Religion \& Health, 46(2), 219-231.

Rammohan, A., Rao, K., \& Subbakrishna, D. K. (2002). Religious coping and psychological wellbeing in carers of relatives with schizophrenia. Acta Psychiatrica Scandinavica, 105, 356-362.

Raykov, T., Tomer, A., \& Nesselroade, J. R. (1991). Reporting structural equation modeling results in Psychology and Aging: Some proposed guidelines. Psychology and Aging, 6(4), 499-503.

Reed-Knight, B., Hayutin, L. G., Lewis, J. D., \& Blount, R. L. (2011). Factor structure of the pediatric symptom checklist with a pediatric gastroenterology sample. Journal of Clinical Psychology in Medical Settings, 18, 299-306.

Richardson, G. E. (2002). The metatheory of resilience and resiliency. Journal of Clinical Psychology, 58(3), 307-321.

Rippentrop, A. E., Altmaier, E. M., Chen, J. J., Found, E. M., \& Keffala, V. J. (2005). The relationship between religion/spirituality and physical health, mental health, and pain in a chronic pain population. Pain, 116, 311-321. doi:10.1016/j.pain.2005.05.008

Robbins, M., \& Francis, L. J. (2009). The spiritual revolution and suicidal ideation: An empirical enquiry among 13- to 15-year-old adolescents in England and Wales. International Journal of Children's Spirituality, 14(3), 261-272.

Rosmarin, D. H., Pargament, K. I., \& Mahoney, A. (2009). The role of religiousness in anxiety, depression, and happiness in a jewish community sample: A preliminary investigation. Mental Health, Religion \& Culture, 12(2), 97-113.

Ryff, C. D. (1989). Happiness is everything, or is it? Explorations on the meaning of psychological well-being. Journal of Personality and Social Psychology, 57(6), 1069-1081. 
Sallquist, J., Eisenberg, N., French, D. C., Purwono, U., \& Suryanti, T. A. (2010). Indonesian adolescents' spiritual and religious experiences and their longitudinal relations with socioemotional functioning. Developmental Psychology, 46(3), 699-716.

Sayeed, A. (2001). Early Sunni discourse on women's mosque attendance. International Institute for the Study of Islam in the Modern World Newsletter. Retrieved from https://openaccess.leidenuniv.nl/bitstream/handle/1887/17457/ISIM_7_Early_Sun ni_Discourse_on_Women_s_Mosque_Attendance.pdf?sequence $=1$

Scales Rostosky, S., Danner, F., \& Riggle, E. D. B. (2008). Religiosity and alcohol use in sexual minority and heterosexual youth and young adults. J Youth Adolescence, $37,552-563$.

Schludermann, E., Schludermann, S., \& Huynh, C. (2003). Religiosity, prosocial values, and adjustment among students in Mennonite high schools in Winnipeg. Journal of Mennonite Studies, 21, 191-213.

Schreiber, J. C. (2013). Religious socialization of maltreated youth and the impact of religiosity on their delinquency. (Unpublished doctoral dissertation). University of Illinois, Urbana, IL.

Shahabi, L., Powell, L. H., Musick, M. A., Pargament, K. I., Thoresen, C. E., Williams, D., Underwood, L., Ory, M. A. (2002). Correlates of self-perceptions of spirituality in American adults. Annals of Behavioral Medicine, 24(1), 59-68.

Simonian, S. J., \& Tarnowski, K. J. (2001). Utility of the pediatric symptom checklist for behavioral screening of disadvantaged children. Child Psychiatry \& Human Development, 31(4), 269-278.

Sinha, J. W., Cnaan, R. A., \& Gelles, R. W. (2007). Adolescent risk behaviors and religion: Findings from a national study. Journal of Adolescence, 30(2), 231-249.

Sisask, M., Värnik, A., Kõlves, K., Bertolote, J. M., Bolhari, J., Botega, N. J., . . Wasserman, D. (2010). Is Religiosity a Protective Factor Against Attempted Suicide: A Cross-Cultural Case-Control Study. Archives of Suicide Research, 14, 44-55.

Slade, S. (2015, July 13). Which religion goes to church the most? Deseret News. Retrieved from http://national.deseretnews.com/article/5152/Which-religion-goesto-church-the-most.html

Socolar, R., Cabinum-Foeller, E., \& Sinal, S. H. (2008). Is religiosity associated with corporal punishment or child abuse? Southern Medical Journal, 101(7), 707-710. doi:10.1097/SMJ.0b013e3181794793 
Steele, C. M., \& Aronson, J. (1995). Stereotype threat and the intellectual test performance of African Americans. Journal of Personality and Social Psychology, 69(5), 797-811. doi:10.1037/0022-3514.69.5.797

Strawbridge, W. J., Cohen, R. D., Shema, S. J., \& Kaplan, G. A. (1997). Frequent attendance at religious services and mortality over 28 years. American Journal of Public Health, 87(6), 957-961.

Suhail, K., \& Chaudhry, H. R. (2004). Predictors of subjective well-being in an eastern Muslim culture. Journal of Social and Clinical Psychology, 23(3), 359-376.

Tarakeshwar, N., \& Pargament, K. I. (2001). Religious coping in families of children with autism. Focus Autism Other Dev Disabl, 16(4), 247-260.

Tarakeshwar, N., Pargament, K. I., \& Mahoney, A. (2003). Initial development of a measure of religious coping among Hindus. Journal of Community Psychology, $31(6), 607-628$.

Tartaro, J., Luecken, L. J., \& Gunn, H. E. (2005). Exploring heart and soul: Effects of religiosity/spirituality on blood pressure and cortisol stress response. Journal of Health Psychology, 10(6), 753-766. doi:10.1177/1359105305057311

Ter Avest, K. H. (2009). Dutch children and their 'God': The development of the 'God' concept among indigenous and immigrant children in the Netherlands. British Journal of Religious Education, 31, 251-262.

Thomas, T. L., \& Freeman, A. (2011). Project Genesis: Self-reported religiosity and spirituality and sexual risk-taking in young African-American women attending a historically African-American college. The Journal of the National Black Nurses Association, 22(1), 27-35.

Tiliouine, H., Cummins, R. A., \& Davern, M. (2009). Islamic religiosity, subjective wellbeing, and health. Mental Health, Religion \& Culture, 12(1), 55-74.

Turner, H. A., \& Kopiec, K. (2006). Exposure to interparental conflict and psychological disorder among young adults. Journal of Family Issues, 27(2), 131-158.

Underwood, L. G., \& Teresi, J. A. (2002). The daily spiritual experience scale: development, theoretical description, reliability, exploratory factor analysis, and preliminary construct validity using health-related data. Annals of Behavioral Medicine, 24(1), 22-33.

Vaaler, M. L. (2008). Family religious involvement and children's mental health outcomes. (Unpublished doctoral dissertation). University of Texas, Austin, TX.

van der Jagt-Jelsma, W., de Vries-Schot, M., de Jong, R., Verhulst, F. C., Ormel, J., Veenstra, R., Swinkels, S., \& Buitelaar, J. (2011). The relationship between 
parental religiosity and mental health of pre-adolescents in a community sample: the trails study. Eur Child Adolesc Psychiatry, 20(5), 253-260.

Van Dyke, C. J., Glenwick, D. S., Cecero, J. J., \& Kim, S. (2009). The relationship of religious coping and spirituality to adjustment and psychological distress in urban early adolescents. Mental Health, Religion \& Culture, 12(4), 369-383.

Vilchinsky, N., \& Kravetz, S. (2005). How are religious belief and behavior good for you? An investigation of mediators relating religion to mental health in a sample of Israeli Jewish students. Journal for The Scientific Study of Religion, 44(4), 459-471.

Walsh, F. (1996). The Concept of Family Resilience: Crisis and Challenge. Family Process, 35, 261-281.

Werner, E. E. (1993). Risk, resilience, and recovery: Perspectives from the Kauai Longitudinal Study. Development and Psychopathology, 5, 503-515.

Williams, N. R., \& Lindsey, E. W. (2005). Spirituality and religion in the lives of runaway and homeless youth: Coping with adversity. Journal of Religion and Spirituality in Social Work: Social Thought, 24(4), 19-38.

Wills, T. A., Yaeger, A. M., \& Sandy, J. M. (2003). Buffering effect of religiosity for adolescent substance use. Psychology of Addictive Behaviors, 17(1), 24-31.

Wolfinger, N. H., \& Wilcox, W. B. (2008). Happily ever after? Religion, marital status, gender, and relationship quality in urban families. Social Forces, 86, 1311-1337.

Yoon, D. P., \& Lee, E. O. (2004). Religiousness/spirituality and subjective well-being among rural elderly whites, African Americans, and native Americans. Journal of Human Behavior in The Social Environment, 10(1), 2004.

Zhang, J., \& Jin, S. (1996). Determinants of suicide ideation: A comparison of Chinese and American college students. Adolescence, 31(122), 451-467. 